University of Nebraska - Lincoln

DigitalCommons@University of Nebraska - Lincoln

Publications, Agencies and Staff of the U.S.

Department of Commerce

U.S. Department of Commerce

2010

\title{
Crucial Role of Mechanisms and Modes of Toxic Action for Understanding Tissue Residue Toxicity and Internal Effect Concentrations of Organic Chemicals
}

\author{
Beate I. Escher \\ University of Queensland, b.escher@uq.edu.au \\ Roman Ashauer \\ Swiss Federal Institute of Aquatic Science and Technology (Eawag) \\ Scott Dyer \\ Procter \& Gamble \\ Joop L. M. Hermens \\ Utrecht University \\ Jong-Hyeon Lee \\ NeoEnBiz \\ See next page for additional authors \\ Follow this and additional works at: https://digitalcommons.unl.edu/usdeptcommercepub \\ Part of the Environmental Sciences Commons
}

Escher, Beate I.; Ashauer, Roman; Dyer, Scott; Hermens, Joop L. M.; Lee, Jong-Hyeon; Leslie, Heather A.; Mayer, Philipp; Meador, James P.; and Warne, Michael S. J., "Crucial Role of Mechanisms and Modes of Toxic Action for Understanding Tissue Residue Toxicity and Internal Effect Concentrations of Organic Chemicals" (2010). Publications, Agencies and Staff of the U.S. Department of Commerce. 259.

https://digitalcommons.unl.edu/usdeptcommercepub/259

This Article is brought to you for free and open access by the U.S. Department of Commerce at DigitalCommons@University of Nebraska - Lincoln. It has been accepted for inclusion in Publications, Agencies and Staff of the U.S. Department of Commerce by an authorized administrator of DigitalCommons@University of Nebraska - Lincoln. 


\section{Authors}

Beate I. Escher, Roman Ashauer, Scott Dyer, Joop L. M. Hermens, Jong-Hyeon Lee, Heather A. Leslie, Philipp Mayer, James P. Meador, and Michael S. J. Warne 


\title{
Crucial Role of Mechanisms and Modes of Toxic Action for Understanding Tissue Residue Toxicity and Internal Effect Concentrations of Organic Chemicals
}

\author{
Beate I Escher, ${ }^{\dagger}, \ddagger$ Roman Ashauer, $\dagger$ Scott Dyer, $\S$ Joop LM Hermens, /| Jong-Hyeon Lee, \# Heather A Leslie, $\dagger \dagger$ \\ Philipp Mayer, $+\ddagger$ James P Meador, $\S \S$ and Michael SJ Warne /II \\ $\dagger$ Department of Environmental Toxicology (Utox), Swiss Federal Institute of Aquatic Science and Technology (Eawag), Überlandstrasse \\ 133, PO Box 611, 8600 Dübendorf, Switzerland \\ $\ddagger$ The University of Queensland, National Research Centre for Environmental Toxicology (Entox), Brisbane, Queensland 4108, Australia \\ §Procter \& Gamble, Cincinnati, Ohio, USA \\ ||Institute for Risk Assessment Sciences, Utrecht University, The Netherlands \\ \#NeoEnBiz, Byeoksan Disital Valley, Seoul, South Korea \\ ††Institute for Environmental Studies, Free University of Amsterdam, The Netherlands \\ ItNational Environmental Research Institute, Aarhus University, Roskilde, Denmark \\ §NOAA Fisheries, Northwest Fisheries Science Center, Ecotoxicology and Environmental Fish Health Program, Seattle, Washington, USA \\ I/||Centre for Environmental Contaminants Research, Commonwealth Scientific and Industrial Research Organisation (CSIRO), Adelaide, \\ South Australia, Australia
}

(Submitted 23 December 2009; Returned for Revision 28 February 2010; Accepted 19 May 2010)

\section{EDITOR'S NOTE}

This paper represents 1 of 6 review articles generated from a SETAC Pellston Workshop entitled "The Tissue Residue Approach for Toxicity Assessment (TRA)" (June 2007, Leavenworth, Washington, USA). The main workshop objectives were to review and evaluate the science behind using tissue residues as the dose metric for characterizing toxic responses and to explore the utility of the TRA for mixtures, guidelines or criteria, and ecological risk assessment.

\section{ABSTRACT}

This article reviews the mechanistic basis of the tissue residue approach for toxicity assessment (TRA). The tissue residue approach implies that whole-body or organ concentrations (residues) are a better dose metric for describing toxicity to aquatic organisms than is the aqueous concentration typically used in the external medium. Although the benefit of internal concentrations as dose metrics in ecotoxicology has long been recognized, the application of the tissue residue approach remains limited. The main factor responsible for this is the difficulty of measuring internal concentrations. We propose that environmental toxicology can advance if mechanistic considerations are implemented and toxicokinetics and toxicodynamics are explicitly addressed. The variability in ecotoxicological outcomes and species sensitivity is due in part to differences in toxicokinetics, which consist of several processes, including absorption, distribution, metabolism, and excretion (ADME), that influence internal concentrations. Using internal concentrations or tissue residues as the dose metric substantially reduces the variability in toxicity metrics among species and individuals exposed under varying conditions. Total internal concentrations are useful as dose metrics only if they represent a surrogate of the biologically effective dose, the concentration or dose at the target site. If there is no direct proportionality, we advise the implementation of comprehensive toxicokinetic models that include deriving the target dose. Depending on the mechanism of toxicity, the concentration at the target site may or may not be a sufficient descriptor of toxicity. The steady-state concentration of a baseline toxicant associated with the biological membrane is a good descriptor of the toxicodynamics of baseline toxicity. When assessing specific-acting and reactive mechanisms, additional parameters (e.g., reaction rate with the target site and regeneration of the target site) are needed for characterization. For specifically acting compounds, intrinsic potency depends on 1) affinity for, and 2) type of interaction with, a receptor or a target enzyme. These 2 parameters determine the selectivity for the toxic mechanism and the sensitivity, respectively. Implementation of mechanistic information in toxicokinetic-toxicodynamic (TK-TD) models may help explain timedelayed effects, toxicity after pulsed or fluctuating exposure, carryover toxicity after sequential pulses, and mixture toxicity. We believe that this mechanistic understanding of tissue residue toxicity will lead to improved environmental risk assessment. Integr Environ Assess Manag 2011;7:28-49. (c) 2010 SETAC

Keywords: Tissue residue approach Mechanisms/modes of toxic action Internal concentration Body residue Toxicokinetics Toxicodynamics

* To whom correspondence may be addressed: b.escher@uq.edu.au Published online 3 June 2010 in Wiley Online Library

(wileyonlinelibrary.com).

DOI: $10.1002 /$ ieam. 100

\section{INTRODUCTION}

Measured tissue residues or internal concentrations of organic chemicals in biological organisms are a better descriptor of toxicity and show less variability, as compared with external exposure-based effect concentrations, with respect to species sensitivity and time dependence of toxicity 
(McCarty et al. 2011). The generally lower variability observed for tissue residue toxicity metrics is primarily a result of their independence of the variability inherent in bioavailability, external toxicokinetics, and bioaccumulation factors. Nevertheless, tissue residues remain only a surrogate for the dose at the target site, termed the biologically effective dose (BED) (Paustenbach 2000). The underlying mechanistic processes determines whether tissue residues are sufficient surrogates of the BED, or if more sophisticated time-resolved toxicokinetic-toxicodynamic models need to be used (Meador et al. 2008; Ashauer and Brown 2008).

In the present work, we review the mechanistic basis of the tissue residue approach for toxicity assessment (TRA) for organic chemicals and explore the benefits and limitations of this approach. As Hendriks et al. (2005) stated, "The lethal body burden concept appears promising but controversial." These investigators also claimed that "The concept has mainly been used for narcotics, and application to other modes of action is limited." Nevertheless, the TRA is being applied in practice, especially in the context of resolved and unresolved mixtures in the environment (Dyer et al. 2011). In addition, environmental quality criteria for organic chemicals are being derived from internal effect concentrations (Traas et al. 2004; Meador 2006).

In this review, we explore why the application of TRA in regulatory risk assessment remains absent or very limited despite many decades of advocacy and recent scientific advances (McCarty and Mackay 1993; Sijm and Hermens 2000; Escher and Hermens 2004; Meador et al. 2008, and references cited therein). We demonstrate that the TRA remains intrinsically limited if it is targeted at determining steady-state, whole-organism concentrations but may further advance if it is focused on target site concentrations and if toxicokinetic and toxicodynamic characteristics are integrated. A number of promising approaches have been proposed in recent years; they have in common that they clearly differentiate between the toxicokinetics and toxicodynamics.

Toxicokinetics encompass many processes, including uptake, distribution to target and nontarget sites, metabolism, and excretion (Figure 1). Owing to toxicokinetic processes, a toxicant reaches its target sites, where the type and degree of interaction determine its toxic effect and potency. The process of toxicant-target interaction and the subsequent effects at the suborganism or organism level, including physiological processes, are called toxicodynamics. The degree and rate of reversibility of the interaction at the toxicant-target site, as well as any compensating mechanisms that result in thresholds or recovery, are determined by the toxic mechanism and the intrinsic potency of a given compound. It is important to note that both organism-specific and species-specific characteristics affect the target, including age, lipid content, and fitness, in addition to numerous species differences.

The literature provides no consistent definition of the terms "toxic mechanism of action" and "mode of action." For the present work, we use the following definitions: A toxic mechanism of action (MeOA) refers to either the crucial biochemical processes, or xenobiotic-biological interactions, or both, underlying a given mode of action (Rand et al. 1995). A mode of action (MoOA) is a common set of physiological and behavioral signs that characterize a type of adverse biological response. The literature often makes no clear distinction between MoOA and MeOA. Inclusion of

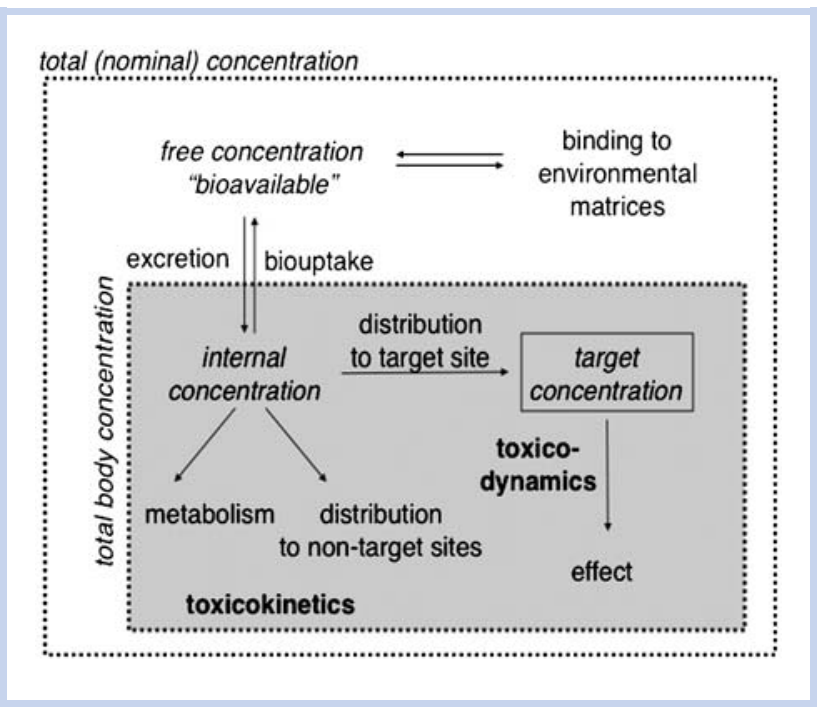

Figure 1. Toxicokinetic processes that determine the internal and target site concentrations of a toxicant. Note that for any given toxicant, multiple compartments and multiple target sites are possible. Very simple case of a single target site. Role of toxicodynamics is also indicated. Adapted with permission from Environ Sci Technol 36:1971-1979. Copyright 2002 American Chemical Society.

mechanistic information in the tissue residue concept must consider the definition of toxic mechanisms. The conceptual idea here is that at a defined occupation of, or reaction with, the target site by a toxicant produces a defined effect. In general, a target site can refer to receptors such as enzyme active sites or a domain (e.g., a membrane lipid bilayer).

The strength of the interaction between a toxicant and the target is an indication of the intrinsic potency of the compound. It is possible to classify toxic mechanisms based on the type and degree of interaction with the target molecule or site (Escher and Hermens 2002). We will review how chemicals can be classified into different toxic mechanisms on the basis of these interactions with the target site. This information can then be related to the chemical structureoriented classification (Verhaar et al. 1992, 1996; Bradbury 1994) to target site-based classification schemes (Nendza et al. 1995; Escher and Hermens 2002; Nendza and Wenzel 2006) and to those derived from physiological observations and modes of action (McKim et al. 1987a; Bradbury 1994).

Measured (whole-body) tissue residues are typically referred to as either critical body residue (CBR) or lethal body burden (LBB). Lethal body burden can be expressed in concentration units but is often also expressed as amount per organism. The terms critical (as in CBR) and effective internal concentrations refer generally to nonlethal or sublethal effects. CBR is also used as a general overarching term to describe any defined adverse toxicity metric. To standardize the nomenclature and provide a more generally applicable terminology, we will refer to such data as the internal effect concentration (IEC) or for mortality endpoints correspondingly internal lethal concentration (ILC), and indicate the critical or lethal endpoint as subscript. IEC and ILC values are typically given in units of mol or $\mathrm{mg}$ toxicant per $\mathrm{kg}_{\text {wet }}$ weight of the animal or tissue.

The general terms IEC and ILC are used synonymously with CBR and LBB, respectively, unless the type of effect is 
further characterized. Any external effect endpoint ECp or $\mathrm{LC} p$, where $\mathrm{p}$ stands for $\mathrm{p} \%$ effect, can thus be converted to the corresponding internal effect concentration eliciting $\mathrm{p} \%$ effect, IECp, or ILCp with knowledge of the ratio of external to internal concentrations. These values are equivalent to the commonly used term effective residue for $\mathrm{p} \%$ effect, ERp. Thus, for example, ILC50 or LR50 refers to the internal concentration that is lethal to $50 \%$ of the test organisms and is analogous to the external LC50, which is defined as the aqueous concentration lethal to $50 \%$ of the test organisms. As another example of the nomenclature, the IEC05 refers to the internal effective concentration that induces a 5\% effect in the population of test organisms. This benchmark of 5\% effect cannot be measured but must be deduced from a full doseresponse curve.

If internal effect concentrations are normalized to a target tissue concentration, this is indicated by a subscript; for example, IEC $50_{\text {membrane lipid }}$ refers to the internal effect concentration in the membrane lipids that induces a $50 \%$ effect.

\section{CLASSIFICATION OF MECHANISMS AND MODES OF TOXIC ACTION}

The interaction of a toxicant with biomolecules at the target site triggers the toxic action (Figure 2). The type and degree of interaction determine the primary action or primary effect that characterizes the toxic mechanism. The cell or organism may respond to this interaction with various detoxification and defense mechanisms (e.g., induction of multifunctional oxidases [MFO] or metallothioneines), but ultimately secondary actions or secondary effects are observable (Escher and Hermens 2002). These observable secondary actions are called modes of toxic action. In principle, the observable secondary actions should be directly proportional to the primary actions, unless delayed induction or breakdown of detoxification and defense mechanisms lead to a nonproportionality between primary and secondary actions. In many published studies, this proportionality is assumed to hold. This is also the likely reason for confusion in the literature regarding the terminology between mechanism and mode of action, with the result that both terms are often used synonymously. For clarity, we try to differentiate systematically between the 2 terms as they are defined in Figure 2; however, the differentiation is sometimes ambiguous even in the proposed framework.

In addition, indirect or delayed effects, or both, may develop. We call these tertiary effects after prolonged exposure to toxicants. These tertiary actions are difficult to quantify and to relate mechanistically to the primary and secondary actions. One example would be a baseline toxicant that produces drowsiness (secondary action), which results in a decreased ability to seek shelter from predators leading to premature death (tertiary action). A tertiary action could also be an irreversible change in the health of an organism that results indirectly from a reversible mode of action, which nevertheless induces additional indirect effects under prolonged exposure. For simplicity, we focus in the present work on primary and secondary effects.

The dynamic energy budget theory (DEBtox) (Kooijman 2000) also uses the term "physiological mode of action" to translate from body residues (at the target site, or inhibition of a target molecule) to effects on life history traits, such as feeding, growth, development, reproduction, and survival (Alda Alvarez et al. 2006). According to this view, each physiological mode of action has a specific effect on the life cycle of an organism, and compounds may exhibit the same molecular mechanism but differ in their physiological mode of action in different organisms (Alda Alvarez et al. 2006). Neuwöhner et al. (2008, 2009) have taken up this terminology to define physiological modes of action in algae, which group endpoints that lead to the same physiological effect (e.g., inhibition of cell division).

Very recently, Ankley et al. (2010) proposed a novel conceptual framework, the "adverse outcome pathways," which is based on the "toxicity pathways" defined for human toxicology (National Toxicology Program 2004; Collins et al. 2008) and which is consistent with, but more detailed than, the general outline displayed in Figure 2. In this concept, primary and secondary actions are termed "toxicity pathways" and are linked to tertiary actions, which are termed "adverse outcome" at the organism or population level, through a cascade of events from cellular response to organ response and finally organism and population response (Ankley et al. 2010). This concept is useful for translating mechanistic information into endpoints meaningful for risk assessment and may help to rationalize previously published schemes for MoOA classification. Table 1 provides an overview and compares the classification schemes used in the literature.

One approach to MoOA classification is to start from the observable symptoms and effects and relate them back to the underlying modes of action. Researchers at EPA Duluth took this approach when they developed so-called "fish acute toxicity syndromes" (FATS). Discriminant function analysis of physiological (McKim et al. 1987b) and behavioral (Drummond et al. 1990) responses of fish, such as heart rate or locomotive activity, resulted in a classification scheme of 8
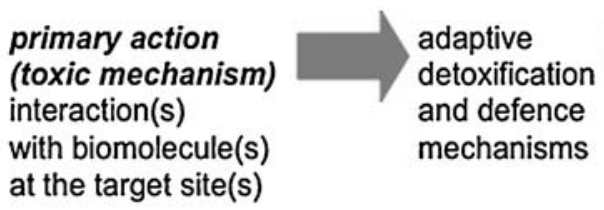

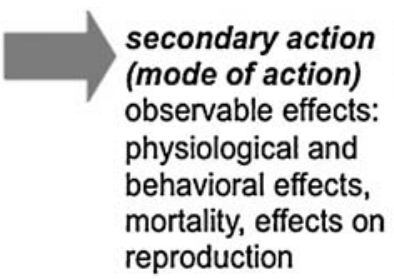

reproduction

tertiary action
indirect and
delayed
effects after
prolonged
exposure, e.g.
increased
predator risk

tertiary action

indirect and

effects after

prolonged

increased

predator risk

Figure 2. Relationship between toxic mechanism of action, mode of action, and tertiary action. 


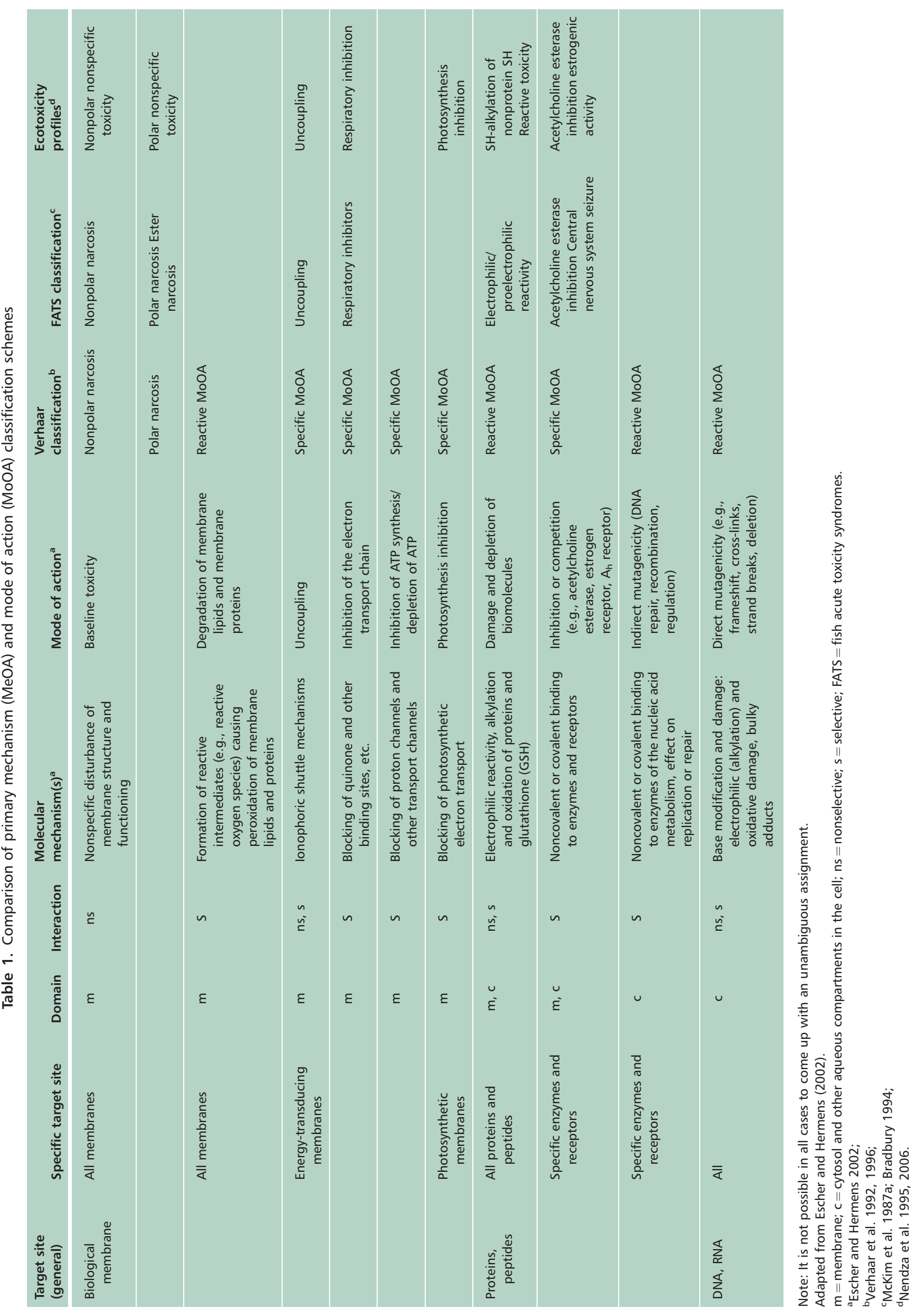


modes of toxic action (McKim et al. 1987a); these are listed in Table 1.

Verhaar and Hermens and colleagues (Verhaar et al. 1992, 1996) used quantitative structure-activity relationship (QSAR) analysis to differentiate between nonspecifically acting, specifically acting, and reactive compounds. In their scheme, nonspecific mechanisms (baseline toxicants) encompass nonpolar and polar narcosis. Nonpolar compounds conform to a QSAR that follows minimal toxicity, with all other mechanisms yielding higher toxicity compared with this QSAR. Polar narcotic compounds are 5 to 10 times more toxic than estimated by the baseline toxicity QSAR and specifically acting and reactive compounds are 10 to 10000 more toxic (Verhaar et al. 1992, 1996). The latter 2 classes cannot be differentiated by QSAR analysis but structural rules serve to differentiate reactive and specifically acting compounds.

Nendza and Wenzel proposed a similar classification scheme based on ecotoxicity profiles and QSAR analysis (Nendza et al. 1995; Nendza and Wenzel 2006), which falls somewhere between the FATS approach (but extended to organisms other than fish) and the chemical structureoriented approach (Verhaar et al. 1992, 1996; Bradbury 1994).

An alternative, bottom-up approach starts by identifying the molecular interaction a toxicant may have with its target molecules or sites (Escher and Hermens 2002). This approach accounts not only for the chemical structure of the toxicant but also for the target, and it relies on simple rules for defining the interactions between toxicant and target. The main targets for toxicants are membrane lipids, proteins and peptides, and DNA. Depending on the type of interaction with the target, it is possible to differentiate between nonspecific effects, when only partitioning to the target site is involved, and specific effects, when interactions between the toxicant and a target molecule are often sterically directed and include specific Hdonor/acceptor interactions as well as ionic interactions. If covalent bonds are formed between the toxicant and target, these are referred to as reactive mechanisms (Escher and Hermens 2002). This generic classification scheme can be further refined by differentiation between more specialized target sites, as shown in Table 1. For example, we can associate toxic mechanisms with proteins and peptides in general, but we can also associate them with specific enzymes and receptors. The first concerns general electrophilic reactivity resulting in the alkylation and oxidation of proteins and related modes of action such as glutathione depletion and the breakdown of the cellular defense system against oxidants. A myriad of specific enzymes and receptors can be described, each of which refers to a specific biochemical process, whose disturbance is related to 1 primary mechanism and corresponding mode of action. Table 1 provides an overview of this classification scheme (Escher and Hermens 2002) and compares it with the other classification schemes available in literature.

Another factor that should be considered is the abundance and activity of receptors that vary between various organs. For example, in most vertebrates the predominant organ associated with biotransformation of toxicants is the liver. Biotransformation does occur in all the tissue types tested; however, extrahepatic tissues (nonliver tissue) have a limited number of enzymes and thus can only biotransform a limited diversity of chemicals (Amdur et al. 1991). These extra- hepatic enzymes also generally have lower activities. The relative capacity of some organs to biotransform toxicants can be characterized in 3 categories: liver (high); lung, kidney, and intestine (medium); and skin, testes, placenta, and adrenals (low) (Amdur et al. 1991). Whereas extrahepatic biotransformation may not contribute significantly to biotransformation as a whole, this is a major factor in toxicant-induced tissue injury.

It is also important to differentiate between reversible and irreversible mechanisms of action. Reversible mechanisms can be related to internal effect concentrations that may or may not be constant over time. In contrast, irreversible mechanisms need other indicators to describe the internal dose metric, for example, a critical depletion rate of a receptor, a critical level (fraction) of affected receptor, or a critical reaction rate for the reaction between toxicant and its target (site). Differing degrees of reversibility can be accommodated by toxicodynamic modeling (Ashauer and Brown 2008).

\section{Baseline toxicity}

Baseline toxicity is believed to be a result of the nonspecific disturbance of the integrity and functioning of cell membranes as a result of chemicals (typically organic pollutants) partitioning into biological cell membranes (Könemann 1981; Veith et al. 1983; Lipnick 1989; Warne et al. 1991; van Wezel and Opperhuizen 1995; Mackay et al. 2009). Chemicals in the membrane are not bound covalently to the membrane but rather are "dissolved" in it. Baseline toxicity caused by the presence of chemicals in the membrane is a reversible mechanism, as was recognized by Meyer and Overton independently more than a century ago (Meyer 1899; Overton 1899). When a cell membrane with baseline toxicants is brought into contact with a medium exhibiting lower fugacity with respect to the toxicant (e.g., transferring an animal from water containing the toxicant to pure water), the toxicant will diffuse out of the membrane, giving the organism a chance to recover rapidly. Note that the reversibility depends on the aqueous solubility and hydrophobicity of a given compound because compounds with limited solubility diffuse to water slowly. Also, this process depends on the physiological status; organisms that are immobilized by baseline toxicants have very slow respiration that limits the diffusion to the excretory membrane, increasing the time to recovery.

With respect to reversibility, baseline toxicity is analogous to the pharmacological mechanism by which anesthetic drugs work (Lipnick 1989; Antkowiak 2001; Moody and Skolnick 2001). The high degree of reversibility of the mechanism means that toxicodynamic recovery is rapid. In fact, it is often assumed that baseline toxicity is instantaneously reversible (i.e., that the effect decreases directly in proportion to the removal of the toxicant from the membrane, without delay). Based on this information, the choice of effect models needs to correspond to this characteristic of baseline toxicity. The nonspecific nature of the mechanism (i.e., partitioning into phospholipid membranes) means that differences between individuals or species are relatively small. Anesthetists and ecotoxicologists both observed a very narrow range of concentrations in the membranes of different patients or species, which cause a given narcotic or baseline toxic response (Seeman et al. 1971; van Wezel and Opperhuizen 1995; Escher and Schwarzenbach 2002). 
Much of the knowledge drawn from pharmacology is relevant in ecotoxicology; therefore, narcosis is a term often used as a synonym for baseline toxicity. We avoid the terms narcosis and anesthesia here because in pharmacology they are used mainly within the context of nerve cells and specific interactions with receptors. Ligand-gated ion channels are the most important target sites for anesthetics in the mammalian central nervous system because they play a key role in neuronal information processing. At higher concentration, a variety of other hydrophobic sites, the interfaces between membrane proteins and the membrane, are also affected (Sandermann 1993; Franks et al. 1994; Krasowski et al. 1999; Antkowiak 2001; Moody and Skolnick 2001).

Although quite a few studies have been conducted on baseline toxicity in ecotoxicology, some unanswered questions remain. In particular, the question of the underlying molecular mechanism of baseline toxicity has not been resolved conclusively. It is commonly accepted that the membrane disturbance is caused by the accumulation of environmental pollutants in hydrophobic phases within the organism, such as membrane lipids (van Wezel and Opperhuizen 1995). Some alternative explanations such as specific protein interactions have also been proposed (Franks et al. 1990).

When narcotic effects are correlated with the octanolwater partition coefficient $\left(K_{\mathrm{OW}}\right)$ as a measure of hydrophobicity, regression equations are found to be significantly different for nonpolar and polar chemicals. On the basis of this finding, it was concluded that 2 mechanisms, i.e., nonpolar and polar narcosis, could be distinguished (Veith and Broderius 1990; Verhaar et al. 1996)

Later studies, however, indicated that the difference between nonpolar and polar narcosis was due to the inappropriate choice of $\log K_{\mathrm{OW}}$, which underestimates the partitioning of polar narcotic compounds between phospholipid cell membranes and water (Vaes et al. 1997, 1998). With the liposome-water distribution coefficient $\left(\log K_{\text {lipw }}\right)$ instead of $\log K_{\mathrm{OW}}$ as the descriptor, QSARs fall on a single line for a series of polar and nonpolar narcotics, suggesting a common mode of action for polar and nonpolar narcotics (Vaes et al. 1998). Urrestarazu Ramos et al. (1998) proposed a mechanistic model for baseline toxicity whereby the toxicant accumulates at the interface between the membrane and the aqueous phase. This hypothesis is supported by molecular dynamics calculations and rationalizes the importance of $\mathrm{H}$-donor-acceptor interactions.

Variability in bioaccumulation between chemicals that act as baseline toxicants has been shown to explain much of the variability in external effect concentrations (McKim and Schmeider 1991; McCarty and Mackay 1993, McCarty et al. 1993). The product of the bioconcentration factor (BCF) and the lethal concentration in the aqueous phase (LC50) was found to be constant for a large number of chemicals; it is therefore commonly referred to as internal lethal concentration (ILC50), used synonymously with lethal residue (LR50) or lethal body burden (LBB). Measured LLBs determined for a series of nonpolar and polar narcotics in fish differed significantly (van Wezel and Opperhuizen 1995); that is, polar narcotic chemicals appeared to have a higher intrinsic toxicity than that of nonpolar narcotics. However, van Wezel and Opperhuizen (1995) attributed the higher intrinsic toxicity of polar narcotics to their different accumulation behavior into nontarget cell constituents as compared with target lipids. This proposal was subsequently shown to be correct by Roberts and Costello (2003), who argued that polar and nonpolar organic compounds still have somewhat different underlying mechanisms because polar compounds intercalate less deeply into membranes and bind via H-bonds to polar head groups of the membrane (2-dimensional partitioning), in contrast to nonpolar compounds, which intercalate deeper into the membrane and can move in all directions in the hydrocarbon core of the membrane (Roberts et al. 2003). Nevertheless, research has shown no clear-cut categorization between nonpolar and polar compounds; rather, there is a gradual transition of polarity.

Membrane concentrations can be modeled via body residues when considering variable amounts of target tissue (van Wezel and Opperhuizen 1995; Vaes et al. 1998). Unfortunately, it is not possible to differentiate between target tissue (membranes) and nontarget storage lipids in a whole organism because the 2 lipid types cannot be separated quantitatively without disturbing the toxicant concentration. To address this concept, Escher et al. (2002) proposed an in vitro test system based on isolated energy-transducing membrane vesicles that permits a direct estimate of the membrane burden of baseline toxicants. These membrane vesicles contain approximately 30\% membrane lipids (dry weight basis) with the remainder as functional proteins. Thus, no storage lipids are involved. Baseline toxicity can be quantified in such an in vitro system by the spectroscopic quantification of the membrane potential, which is destroyed in the presence of baseline toxicants. The results of this study clearly indicated that there are equal effective membrane concentrations of nonpolar and polar compounds on the order of 220 to $470 \mathrm{mmol} / \mathrm{kg}_{\text {lip }}$ (Escher et al. 2002), confirming the hypothesis of van Wezel and Opperhuizen (1995) and supporting the work of Vaes et al. (1998).

These results encouraged further modeling studies and a large data set of measured total internal effect concentrations from various literature sources was modeled with a simple 3compartment model (Eqn. 1).

$$
\begin{aligned}
& \text { IEC }_{\text {membrane lipid }} \\
& =\frac{\mathrm{IEC}_{\text {total }} \cdot K_{\text {lipw }}}{f_{\mathrm{w}}+f_{\text {membrane lipid }} \cdot K_{\text {lipw }}+f_{\text {storage lipid }} \cdot K_{\text {hw }}}
\end{aligned}
$$

The model assumed that each aquatic organism was composed of membrane lipids, storage lipid, and a waterlike compartment (Escher and Schwarzenbach 2002). The liposome-water partition coefficient $K_{\text {lipw }}$ serves as the model parameter to model uptake into membrane lipids; the hexane-water partition coefficient $K_{\mathrm{hw}}$ serves as model parameter to model uptake into storage lipids. Parameters $f_{\mathrm{w}}, f_{\text {membrane lipid, }}$ and $f_{\text {storage lipid }}$ describe the fraction of chemicals in water, storage lipids, and membrane lipids, respectively. Figure 3 illustrates this simple model for fish and depicts a compilation of results (details can be found in Escher and Schwarzenbach 2002).

As is evident from Figure 3, the total internal effect concentration $\mathrm{IEC}_{\text {total }}$ given in units of $\mathrm{mmol} / \mathrm{kg}_{\text {wet weight }}$ is slightly higher for nonpolar than for polar compounds. This difference led initially to the hypothesis that there are 2 different types of narcotic mechanisms (McKim et al. 1987a). However, the small difference in IEC $_{\text {total }}$ is attributable to a large difference in $\mathrm{IEC}_{\text {storage lipids }}$ between nonpolar and polar 


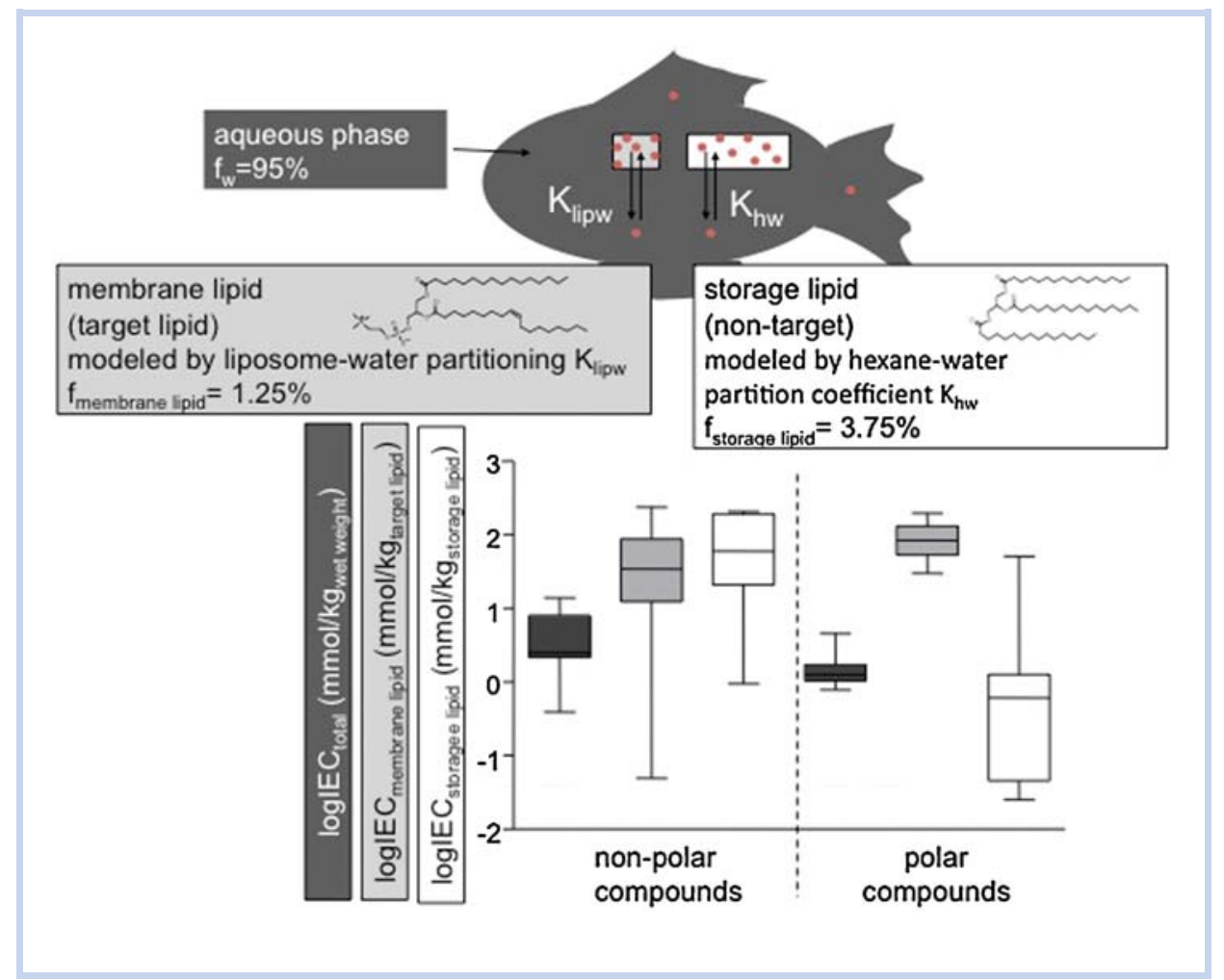

Figure 3. Three-compartment model to assess the target site concentration of baseline toxicants. Data and model taken from Escher and Schwarzenbach (2002). Graph shows boxes, which extend from the 25th to the 75th percentile, with a horizontal line marking the median. Whiskers extend above and below the boxes to the highest and lowest value. Number of data points is 19 for nonpolar compounds and 14 for polar compounds. $f=$ fraction of lipid.

compounds, whereas the modeled membrane burdens

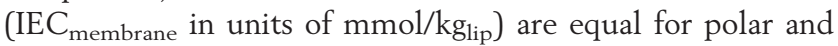
nonpolar compounds, confirming that there is no difference in toxic mechanism between polar and nonpolar compounds (Vaes et al. 1998).

The database for aquatic organisms is much weaker other than for fish. However, in principle, the same modeling approach can also be taken for algae and Daphnia. The problem is that fewer studies are available that have measured the lipid content of algae and Daphnia at the same time as the toxicity studies, so assumptions regarding the lipid content must be derived from other studies. Figure 4 illustrates that even between different aquatic species there is no significant difference between the target-lipid normalized IEC $_{\text {membrane }}$ lipid, even if effects were assessed at different times and life stages. Again, the concentration of toxicant in storage lipid varies over several orders of magnitude between polar and nonpolar compounds for Daphnia, too, but for algae no storage lipids are included. Hendriks et al. (2005) extended the data set to additional aquatic species, including plants, annelids, mollusks, and arthropods, and found a consistent picture when modeling target lipid concentrations. These examples demonstrate that even for a very simple mechanism, such as baseline toxicity, total lipid normalized internal concentration is not a perfect surrogate for the concentration at the target site in the membrane because of subtle differences in partitioning between lipid bilayers and bulk storage lipids.

Several studies have shown that under laboratory conditions, the ILC of baseline toxicants that leads to mortality of the test organism is constant in time and that this is not dependent on the exposure time (Leslie et al. 2004, and references therein, e.g., Abernethy et al. 1988; Warne et al. 1991; McCarty and Mackay 1993). In these tests, organisms began to absorb the chemical from their surroundings in a process driven by a combination of the fugacity gradient and the relatively large affinity of the chemical for the organism. The organisms continued to absorb the chemical until steady state or death was reached, whichever came first. Accordingly, the time dependence of toxicity of baseline toxicants can be described by a simple toxicokinetic model that assumes bioconcentration as a first-order kinetics 1-compartment model and a constant body residue for the same effect level, independent of exposure duration (constant ILC) after toxicokinetic steady state is obtained (van Hoogen and Opperhuizen 1988). The baseline effect is instantaneously reversible, so the time course of effects is governed purely by toxicokinetics for nonconstant exposure conditions. A more detailed discussion on toxicokinetic models can be found below.

The literature does contain studies, however, asserting that baseline toxicants have a second kinetic step, i.e., that internal effect concentrations do not remain constant over time (Chaisuksant et al. 1997, 1999; Lee et al. 2002; 2003). In fact, these articles reported that the closer the exposure time gets to the life span of the organism, the smaller the ILC50 (Chaisuksant et al. 1999).

As exposure time is prolonged, tertiary effects could arise after the primary effect (disturbance of the membrane) and secondary effect (narcosis) occurred, even for baseline toxicants. These effects could be postulated to arise not from increased damage to the membrane (the site of action) over time, but from effects on an organism's life caused by suppression of the central nervous system associated with 


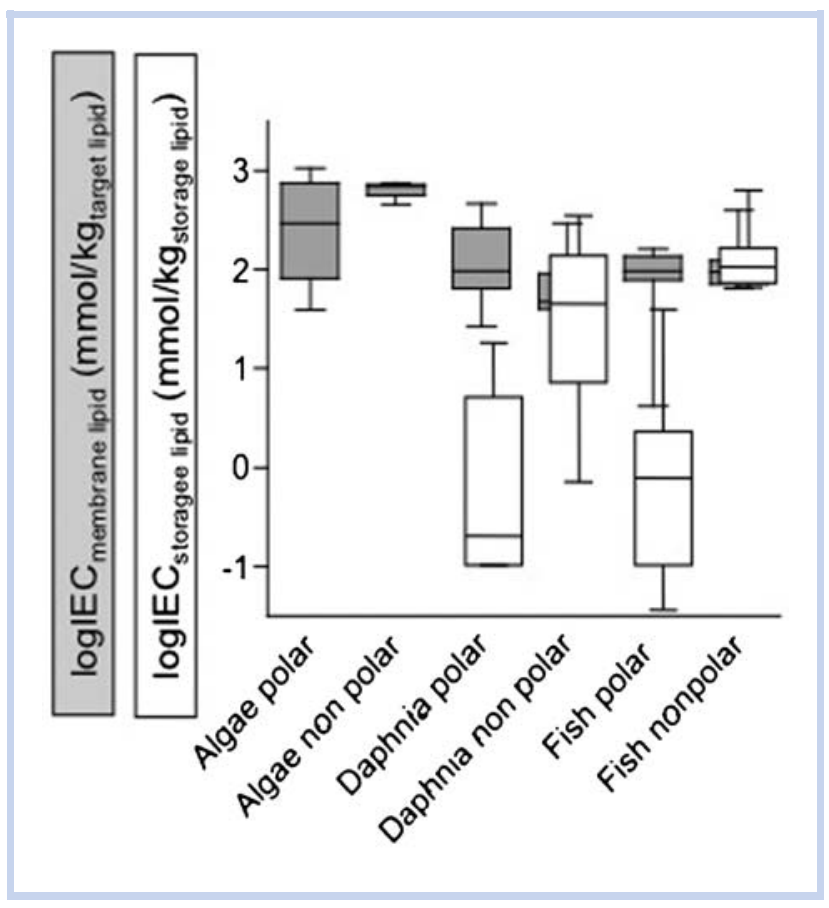

Figure 4. Comparison of IEC50 ${ }_{\text {membrane lipid }}\left(\mathrm{mmol} / \mathrm{kg}_{\mathrm{lip}}\right)$ and $\mathrm{IEC} 50_{\text {storage lipid }}$ $\left(\mathrm{mmol} / \mathrm{kg}_{\text {lip }}\right)$ of polar and nonpolar narcotic chemicals in algae (membrane lipid only), daphnids, fish, and the Kinspec system (membrane lipids only). Graph shows boxes, which extend from the 25th to the 75th percentile, with a horizontal line marking the median. Whiskers extend above and below the boxes to the highest and lowest value. Graph modified from and data compiled by Escher and Schwarzenbach (2002).

narcosis. In the field, prolonged exposure could result in loss of alertness, leading to increased predation, modified behavior, delayed or inhibited mating, and decreased ability to find sufficient food (indirect or tertiary effects).

It is important to note that the internal concentrations required to elicit baseline toxicity are relatively high, in the range of $50 \mathrm{mmol} / \mathrm{kg}_{\text {membrane lipid }}$ (see data shown in Figure 3).

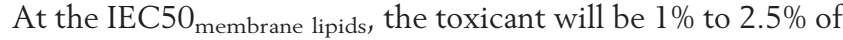
the membrane (see also Abernethy et al. 1988), and we can expect membrane expansion and other related effects. Also, with membrane burdens so high, it is sometimes difficult to reach them in an experiment with a single chemical, and such measurements are highly prone to artifacts.

Despite the limitations described above, the baseline toxicity concept is very useful in developing a conceptual understanding of the toxic effects of mixtures. As discussed in greater detail in the accompanying article on mixture toxicity (Dyer et al. 2011), the toxicity of mixtures of chemicals each with baseline toxicity is always internal-concentration additive. In addition, for mixtures of large numbers of compounds with various different mechanisms, it is likely that the specific effects of specific components of the mixture do not dominate, but the additive effect on the underlying baseline toxicity dominates the overall mixture effect (Hermens et al. 1982; Warne and Hawker 1995).

\section{Tissue residues for compounds eliciting specific molecular mechanisms}

Target tissue residues are more uniform over species and time than are aqueous effect concentrations because they account for differences in toxicokinetics between different species. In general, the IECs of specifically acting and reactive compounds are lower than those of baseline toxicants and appear to vary more between different aquatic species. (See Figure 5, which shows experimental data from the literature compiled by Hendriks et al. 2005.) Line a in Figure 5 refers to a compilation by the authors of the study from various literature sources; line $b$ refers to the compilation of fish data by McCarty and Mackay (1993). Line c in Figure 5 is an extremely diverse compilation of literature data by Barron et al. (2002) (hence the much wider ranges than for the other data compilations), and line $\mathrm{d}$ represents data from the Environmental Residue/Effects Database ([ERED] http:// www.wes.army.mil/el/ered/index.html) compiled by Traas et al. (2004). Note that this database is based on MoOA, and not on primary mechanisms; this contributes to the increased variability because several different molecular mechanisms (MeOA) can be integrated under 1 MoOA. In addition, multiple responses are combined, contributing to the variability.

The greater variability within and between the different specific MoOAs stems from differences in toxicodynamics. For baseline toxicants, the effective target concentration is essentially equivalent for every chemical. Specifically acting and reactive compounds have different total internal and target site concentrations for different MoOAs, and even within a given $\mathrm{MeOA}$, because the intrinsic potency might vary. For example, the same concentration at the target site may produce a high variability in toxic response among individuals or species. An example of this is uncoupling of oxidative phosphorylation. For this MoOA, the potency of an uncoupler is determined by the concentration at the target site in addition to the energy barrier for crossing the energytransducing membrane (Spycher et al. 2008). Studies with compounds inhibiting acetylcholinesterase irreversibly provide further evidence that toxic effects for those specifically acting compounds cannot be explained by internal concentrations (Ashauer et al. 2010b).

Differences in the sensitivity of organisms to a toxicant can arise through 2 means. First is the presence or absence of the target site required for the MeOA to exert its effects. Second, differences in the quantity and activity of the target site and/ or defense mechanisms can modify the MoOA and thus the overall sensitivity, even though the toxicant exerts its effect by the same molecular mechanism (Escher and Hermens 2002). An example of the former is herbicides that will manifest their specific MeOA in photosynthetic organisms but that act by a nonspecific MoOA for organisms without photosynthetic systems. Life stage differences within a species is another consideration. For example, enzyme systems such as CYP1A or PCY450 may not be fully expressed in the egg but may be present in the adult. Consequently, whole-body toxicity metrics for chemicals with specific MeOAs are less adequate surrogates for toxicity based on target tissue concentrations than are observed for chemicals exhibiting baseline toxicity. However, given the drawbacks, these metrics are acceptable surrogates in many instances.

In addition, although baseline toxicity is fully reversible (unless tertiary irreversible damage arises in other targets as a result of prolonged exposure), specific and reactive $\mathrm{MeOAs}$ differ in their degree and speed of reversibility. Typically for compounds with reversible MeOAs, the effects are instantaneous and responses are observed if a critical concentration of affected target site molecules is produced. The importance of 


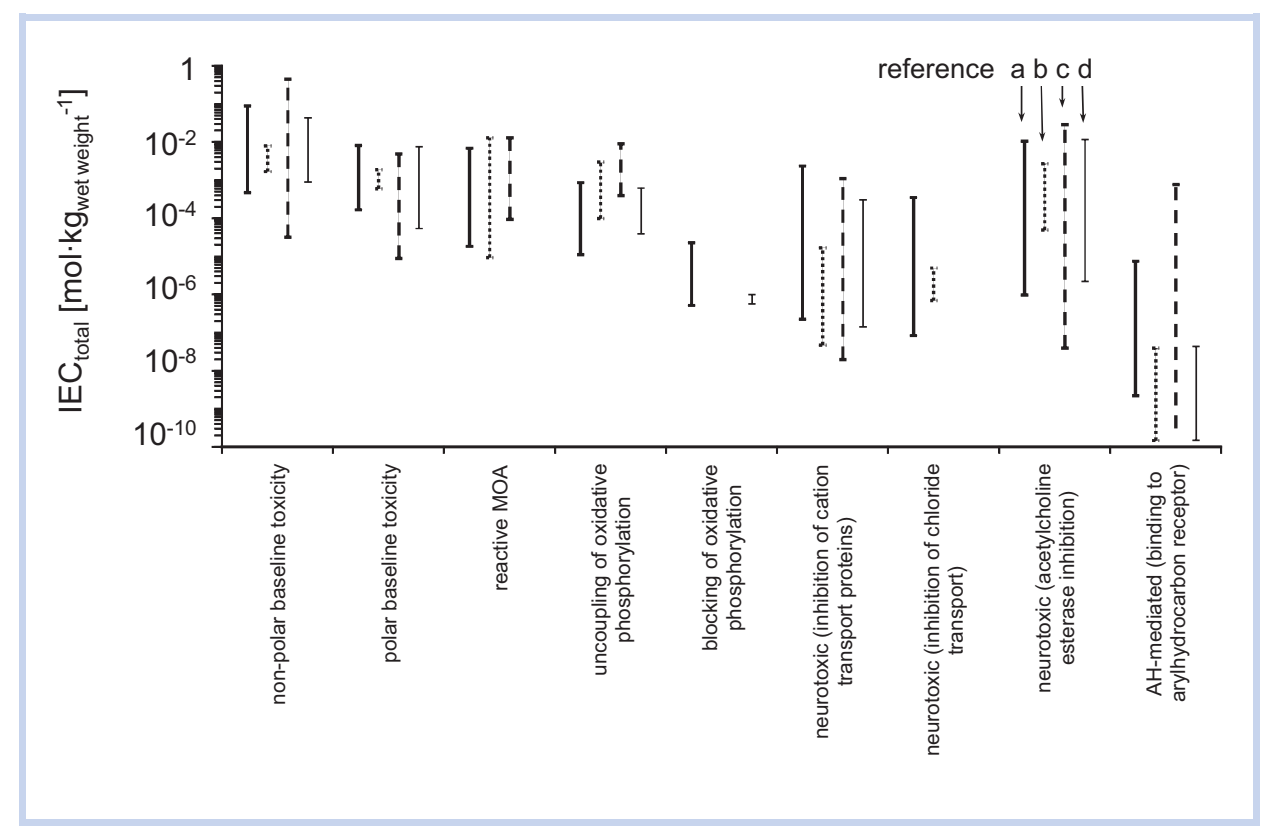

Figure 5. Total tissue internal effect concentrations IEC total $\left(\mathrm{mol} / \mathrm{kg}_{\text {wet weight }}\right)$ for various species and 9 different mechanisms of action (MoOAs) Lines a- $\mathrm{d}$ within the data for each MoOA refer to data compilations for different species; a- drawn line: data compiled by (Hendriks et al. 2005); b- dotted line: data compiled by (McCarty et al. 1993), c-dashed line: data compiled by (Barron et al. 2002), and d- thinner drawn line: data compiled by (Traas et al. 2004); a and d represent 5 to 95 percentiles, and b and c are the minimum and maximum values. Adapted with permission from Environ Sci Technol 39:3226-3236. Copyright 2005 American Chemical Society.

toxicodynamics depends on the speed and reversibility of both the MeOA and MoOA (Ashauer and Brown 2008). Time dependence of the effect of quickly and fully reversibly acting toxicants may be dominated by toxicokinetics; however, toxicodynamics may play an additional role for MeOAs characterized by slow or incomplete reversibility. Conceptually, this can be visualized by a gradual occupation of target sites and, in the case of fluctuating or pulsed exposure concentrations, regeneration of target sites. If a critical concentration of toxicant is reached at the target site (i.e., a critical percentage of target sites are occupied) for a critical duration, a toxic effect is elicited.

The intrinsic potency of a toxicant can be expressed by the toxic ratio (TR) (Eqn. 2) (previously called the excess toxicity, Te), which is the ratio between the predicted IEC for baseline toxicity to the experimental IEC (Lipnick et al. 1987). We have modified this equation for internal concentration as follows:

$$
\begin{aligned}
\mathrm{TR} & =\frac{\mathrm{EC}_{\text {baseline toxicity, } \mathrm{QSAR}}}{\mathrm{EC}_{\text {experimental }}}=\frac{\mathrm{BCF} \cdot \mathrm{EC}_{\text {baseline toxicity, } \mathrm{QSAR}}}{\mathrm{BCF} \cdot \mathrm{EC}_{\text {experimental }}} \\
& =\frac{\mathrm{IEC}_{\text {baselinetoxicity, } \mathrm{QSAR}}}{\mathrm{IEC}_{\text {experimental }}} .
\end{aligned}
$$

The external concentration-based EC for baseline toxicity can be predicted using a QSAR for baseline toxicity. The TR for a compound derived using the external effect concentrations (EC) or the internal effect concentrations (IEC) will be the same because the IEC is related to the $\mathrm{EC}$ via the $\mathrm{BCF}$. For the TR, using internal concentration, the BCF terms cancel out. This simplified picture holds only for nonmetabolizable compounds. In addition to biotransformation, deviations may also occur if accumulation in compartments other than storage lipids is important, which is the case for lean organisms or substances with affinity for proteins. The latter issue can be addressed by a slightly more detailed modeling effort that relates the affinity of substances with specific compartments (e.g., polar lipids, neutral lipids, proteins, lignin) using the appropriate partition coefficients (Escher and Hermens 2002).

The intrinsic potency of a reactive compound will depend on parameters such as the tendency to react with a specific biological molecule (selectivity) and the rate of reaction (sensitivity). For reactive toxicants with selective reactivity in particular, this tendency is related to the electrophilicity and nucleophilicity of the toxicant. For specifically acting compounds, intrinsic potency depends on the affinity for (selectivity) and type of interaction with (sensitivity) a receptor or a target enzyme.

\section{Reversible specific mechanisms}

For completely and instantaneously reversible specific mechanisms, the effective or critical target concentrations should be uniform for a given toxicant and should not depend on exposure time, but they do differ for different chemicals. Examples include inhibitors of Photosystem II (PSII) such as phenylureas and triazines. Each PSII inhibitor has a different affinity to the target site, but the effects are rapid and reversible; thus the total internal concentration is relatively invariant over an extended period of time. Complete recovery of algal photosynthetic activity has been observed after treatment with short pulses of PSII inhibitors (Vallotton et al. 2008). As for baseline toxicants, any time dependence of toxicity is explained mainly by the elimination kinetics. Slow elimination kinetics dictates the degree of reversibility and the rate at which the organism reaches equilibrium. With very 
prolonged exposure (i.e., approaching the life span of the organism), tertiary effects may cause the critical target concentration for each chemical to vary, as was noted by (Chaisuksant et al. 1997; Yu et al. 1999; Lee et al. 2002).

Another example of reversible specifically acting compounds are uncouplers of oxidative phosphorylation, in particular the protonophoric uncouplers like the weak phenolic acids pentachlorophenol or dinoseb (2-sec-butyl4,6-dinitrophenol). These compounds destroy the electrochemical proton gradient, which delivers energy to the ATP synthesis biochemical reactions by transporting protons across the membrane. The uncoupling activity is dependent on the abundance of uncouplers in the energy-transducing membranes but also on the speciation of the weak organic acid. This is because both the neutral acidic and the charged basic species need to be present for efficient uncoupling (Terada 1990), resulting in a strong dependence of uncoupling activity on $\mathrm{pH}$ (Escher et al. 1999). Even if 2 uncouplers are present in the membrane at equal concentrations and equal ratios of the acidic and basic species, intrinsic potency differences can remain. The intrinsic potency of an uncoupler is determined by the membrane permeability of both neutral and charged species. If the energy barrier of the charged species for crossing the membrane is too high, uncoupling will be slow and uncoupling inefficient (Spycher et al. 2005).

For partially reversible mechanisms with noninstantaneous reversibility, both the critical target site concentration as well as the exposure duration matter. Acetylcholine esterase inhibitors illustrate this case. Whereas carbamates bind reversibly to the target site, the enzyme acetylcholine esterase (AChE), the binding of organophosphates is rapid but the release is slow, especially if the enzyme-inhibitor complex "ages," i.e., further ester groups hydrolyze (Timbrell 2000). Therefore, organophosphates are considered irreversibly acting AChE inhibitors (Legierse et al. 1999), and carbamates are considered reversibly acting AChE inhibitors.

\section{Irreversible specific mechanisms}

For irreversible specific and reactive mechanisms, the time dependence of effects is more complex and will not be explored in this review. For these situations, the time integral of occupied targets might be a better internal exposure parameter than the equilibrium target concentration. For such mechanisms, there may be no constant critical IEC because of the considerable dependence on exposure duration, but other parameters may still serve the purpose of defining effects in an independent way, such as the reaction rate with the target site. Returning to the example of the AChE inhibitors, Legierse et al. (1999) proposed as an alternative measure of target occupation the critical area under the curve (CAUC), i.e., the time-integrated internal concentration. The toxic effect occurs at a defined CAUC, and this can be associated with a higher exposure concentration over a shorter time or a lower exposure concentration over longer time, as illustrated in Figure 6. With this model, it was possible to rationalize the time dependence of toxicity of a series of irreversible AChE inhibitors in various organisms, such as chlorothion in the pond snail and methidathion in guppy (Legierse et al. 1999). CAUC is approximately constant for a single compound but varies between different compounds because of differences in intrinsic potency.

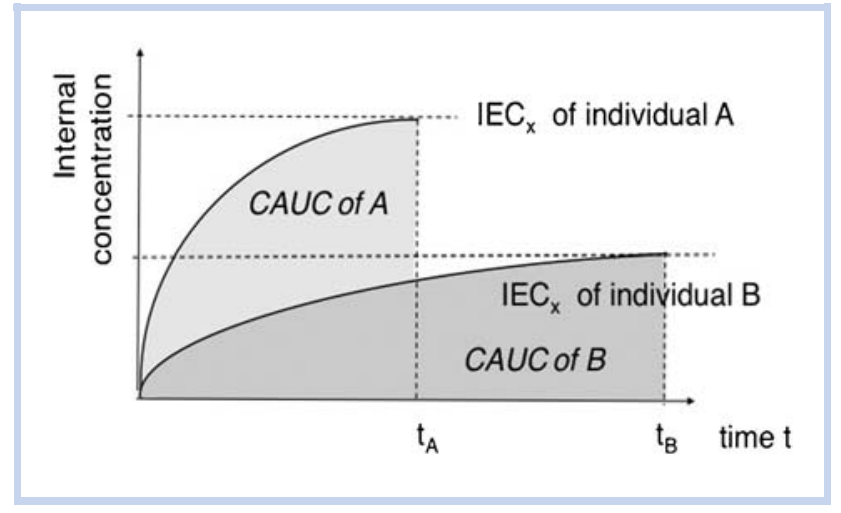

Figure 6. Critical target occupation model. Measure of effect is the timeintegral of the internal concentration, the so-called critical area under the curve (CAUC). Adapted with permission from Environ Sci Technol 33:917-925. Copyright 1999 American Chemical Society.

Despite the additional complexity when dealing with irreversible specific mechanisms, the TRA facilitates characterization of the exposure at the target sites. Hence it is still useful in analyzing the time dependence of, and relationship between, occupied target sites and elicited toxic effects.

\section{Reactive mechanisms}

Reactive mechanisms refer to electrophilic reactivity toward biological nucleophiles such as proteins and DNA, or to effects related to oxidative stress. Oxidative stress is a cascade of events that are too difficult to describe with the approaches presented in the present work (or again, specific surrogate measures have to be defined). However, the electrophilic reactivity toward biological nucleophiles can be explained in a straightforward manner if one assumes a critical target reaction rate (Verhaar et al. 1999).

For reactive chemicals there is again no critical tissue residue because the toxicants may react directly with their biological targets in such a manner that the compound may not even be detected in the tissue. In such cases, the critical reaction rate with the target site and the depletion of unoccupied target sites are alternative measures of internal exposure, and the critical target occupation (CTO) model can also be applied to reactive mechanisms (Verhaar et al. 1999). Reactive mechanisms involve the formation of covalent bonds and are generally irreversible.

Freidig et al. (1999) measured the depletion rate of glutathione in an in vitro system and used this indicator to rank the toxic potencies of a series of acrylates. By comparing the depletion rates with fish LC50 data, a critical depletion rate was defined. This approach was successful because the site of action in the in vitro system as well as in vivo is situated in the aqueous phase, making exposure in both systems very similar. Another major advantage of such an approach is that the total response reflects the overall toxicity of a mixture of the reactive acrylates in a similar way as total body residue does for narcosis.

Harder, Escher, and Schwarzenbach (2003) built on this work and proposed to use the reaction rates of electrophilic chemicals toward model biological nucleophiles as indicators of toxicity. The model nucleophiles were deoxyguanosine and glutathione, which served as surrogates for DNA bases and proteins and/or peptides. The reaction rates allowed an 
estimate of the toxic potency, but also a classification according to the selectivity of the electrophilic reaction (Harder, Escher, Landini, et al. 2003; Harder, Escher, Schwarzenbach 2003). Whereas soft electrophiles like acrylates are more reactive with proteins and peptides, hard electrophiles like styrene oxide react with the DNA bases.

\section{Chemicals with more than one mode of action}

Chemicals may have more than one mechanism and mode of action. The most well-known example for multiple MoOA is that some specific-acting organic chemicals may contribute to baseline toxicity. In many cases, this baseline toxicity is overwhelmed by a specific mechanism of action, and baseline toxicity action will not be apparent. The TR can be used as an indicator for the potential contribution of baseline toxicity when examining TR-based toxicity data. If the TR is $>10$, baseline toxicity does not play a role at all in a toxicity test with individual organisms. But if the TR is closer to 1 , baseline toxicity will become part of the overall effect.

Baseline toxicity can become relevant in several cases. One interesting example is when the concentration of a reactive or specifically acting chemical at the site of action in a hydrophilic environment is too low to exert the specific toxicity. This will be applicable for more hydrophobic reactive chemicals because their concentrations in a more hydrophobic environment (e.g., the cell membrane) will be relatively high. In such cases, the less intrinsically potent baseline effect will dominate the reactive toxicity. Several examples of studies with reactive chemicals support this interesting hypothesis. Experimental toxicity data for less hydrophobic reactive chemicals often have relatively high TR values, whereas the TR for the more hydrophobic reactive compounds are often lower and approach 1 (Deneer, Seinen, Hermens 1988a; Deneer, Sinnige, et al. 1988b; Freidig et al. 1999). This same trend is observed for organophosphates (Freidig and Hermens 2001) (Table 2). The TR is close to 1 for the 3 most hydrophobic (and thus sterically bulky) organophosphates (iodophenphos, bromophos, and ronnel), and these compounds most likely act via the baseline toxicity

Table 2. Relative contribution of baseline and specific mechanisms of action (MeOA) to the toxicity of selected organophosphates (Freidig et al. 2001)

\begin{tabular}{|lccl|}
\hline Organophosphate & Log $\mathcal{K}_{\text {ow }}{ }^{\mathrm{a}}$ & $\mathrm{TR}^{\mathrm{b}}$ & $\begin{array}{l}\text { Dominant toxic } \\
\text { mechanism }\end{array}$ \\
\hline lodophenphos & 5.51 & 0.57 & Baseline toxicity \\
\hline Bromophos & 5.21 & 1.8 & Baseline toxicity \\
\hline Ronnel & 5.07 & 2.9 & Baseline toxicity \\
\hline Fenitrothion & 3.47 & 7.1 & Unclear \\
\hline Methylparathion & 3.04 & 41.2 & AChE inhibition \\
\hline Malathion & 2.94 & 89.6 & AChE inhibition \\
\hline
\end{tabular}

As the toxic ratios decrease to $<10$, the contribution of the baseline MeOA to the toxicity increases. Once the TR is $>10$, the baseline MeOA contributes very little to the toxicity of the chemical.

${ }^{\mathrm{a}} \mathrm{K}_{\mathrm{ow}}$ : octanol-water partition coefficient.

${ }^{\mathrm{b}}$ Toxic ratio TR is defined by Eqn 1, where $\mathrm{LC} 50_{\text {baseline toxicity, QSAR }}$ was calculated based on a QSAR for baseline toxicity for the specific organism (in this case guppy) (Freidig et al. 2001). mechanism. The 3 other organophosphates (fenitrothion, methylparathion, and malathion) are less hydrophobic, and the TR is much higher. The toxic mechanism of these chemicals is likely to be predominantly by their specific $\mathrm{MeOA}$, i.e., inhibition of acetylcholine esterase (AChE).

A second example occurs in complex mixtures with numerous different chemicals when the small contribution by the baseline toxicity of each chemical may lead to a significant toxic effect; this is because baseline toxicity is always concentration additive and different specific MoOAs are not (Warne and Hawker 1995). Dyer et al. (2011) present a more thorough discussion of this phenomenon. The advantage of using the internal effect concentrations is that in mixtures the body residues can simply be added up. Earlier work has shown that in LC50 tests for equitoxic mixtures (all mixture components present in concentrations that elicit the same contribution to the mixture effect) of 8 to 24 chemicals with specific $\mathrm{MeOAs}$, the contribution of the baseline toxicity $\mathrm{MeOA}$ can be up to 30\% (Hermens et al. 1982).

As a third example, if the potency for the specific $\mathrm{MeOA}$ is not much higher than the potency for baseline toxicity, this second MeOA will contribute significantly to the overall effect. For example, the mechanism of protonophoric uncoupling (MoOA uncoupling of oxidative phosphorylation) changes into baseline toxicity when at the $\mathrm{pH}$ of the experiment the neutral species dominates the charged species (Escher et al. 1999; Escher and Schwarzenbach 2002). Finally, time may be a factor. In some cases, it may take longer for the response to develop for $1 \mathrm{MeOA}$ compared with another.

Another interesting example of chemicals having multiple MoOAs is the lethal toxicity of organotin compounds that are respiratory uncouplers and respiratory inhibitors. However, in practice it is difficult to differentiate between these 2 modes of action and assess which is dominant because of mitigating factors. First, the underlying toxic mechanisms occur at energy-transducing membranes such as mitochondrial membranes or photosynthetic membranes. Second, different mechanisms are possible that could underlie the observed MoOAs. By using isolated membrane vesicles of a photosynthetic bacterium as test system, it was possible to differentiate between uncoupling by a hydroxide uniport mechanism and direct inhibition of the ATP synthetase (Hunziker et al. 2002). The result of this study clearly indicated that the acute effect of tributyltin is dominated by uncoupling, whereas the acute effect of triphenyltin is dominated by direct inhibition of ATP synthetase (Hunziker et al. 2002). This difference can again be explained in terms of the affinity of the 2 organotin compounds for the target sites. The membrane-water partitioning of tributyltin follows its hydrophobicity and is consequently driven mainly by partitioning into the membrane; in contrast, triphenyltin has a much higher affinity for membranes than would be expected by its hydrophobicity (Hunziker et al. 2001). Triphenyltin forms stronger complexes with oxygen ligands than tributyltin, which explains the stronger binding of triphenyltin to membranes than can be predicted by partitioning because binding is through complex formation, but it also explains the higher affinity of triphenyltin to the ATP synthetase. Consequently, triphenyltin is a more potent inhibitor of the enzyme, and tributyltin is a more potent uncoupler. Despite the differences in the molecular mechanism of toxicity, the observable MoOA is the same. This example focuses on the 
lethal action of triorganotins on energy transduction. However, the organotins exhibit additional MoOAs, as discussed by Meador (2006), such as immunotoxicity and endocrine disruption, through binding to the retinoid $\times$ receptor $(\mathrm{Nish}$ ikawa et al. 2004).

\section{DOSE METRICS OF INTERNAL EXPOSURE}

\section{Tissue concentrations}

The internal exposure of pollutants can be determined and expressed by several methods. Tissue concentrations on a wet weight or dry weight basis are the most directly observable measure of internal exposure. They are obtained by extracting tissue samples with suitable solvent (e.g., dichloromethane for apolar organics and hydrochloric acid for metals) followed by instrumental analysis.

Such measured tissue concentrations can be normalized by the lipid fraction of the tissue. At least 3 important issues should be addressed with regard to such normalization. First, normalization is only meaningful when the sorptive capacity of the tissue is adequately represented by the normalizing parameters (e.g., lipid fraction) (Schwarzenbach 2003). This requirement is important to ensure the general agreement between lipid-normalized concentrations and the actual concentrations in the lipid. De Bruyn and Gobas (2007) demonstrated that if chemicals bind to proteins, normalization procedures that only consider the lipid fraction are not sufficient. By contrast, normalizing exclusively to protein will not work because partitioning of hydrophobic compounds to membranes can never be neglected.

Second, normalized concentrations should also preferably be directly related to the pollutant concentration at the target site. It is important to realize that storage lipids often dominate the sorptive capacity of animal tissue for many hydrophobic chemicals, whereas lipid membranes often are considered their target site. A mismatch between the partitioning properties of these 2 types of lipids will thus introduce error into the internal exposure response relationship, as was discussed above.

Third, normalization procedures require measurements of additional input parameters such as the lipid fraction and the dry weight content. The application of these parameters introduces additional error into the internal exposure value.

\section{Biomimetic extractions and free concentrations}

Extraction of organic contaminants from tissue remains tedious work. The difficulty of measuring internal concentrations and TRs remains one of the greatest obstacles in the application of the TRA. Internal exposure can be determined and expressed in a number of alternative ways, including chemical methods that mimic uptake into organisms (e.g., biomimetic extractions). Partitioning-based sampling techniques can be tailored to mimic the uptake from the external exposure media and into an organism. Such techniques are often referred to as biomimetic extractions using passive samplers. Examples of these passive samplers include C18coated Empore $^{\mathrm{TM}}$ disks (Verhaar et al. 1995), semipermeable membrane devices (SPMD) (Huckins et al. 1990), solid-phase microextraction fibers (SPME) (Leslie et al. 2002), and polydimethylsiloxane (PMDS) (Smedes, 2007). Frequently, the kinetics of uptake into, and elimination from, an organism are different from the corresponding kinetics for a sampler, and calibration is needed.

Recently, it was suggested that passive samplers be used directly within animal tissue and body fluids. Thin polymer coatings can be equilibrated directly with animal tissue to determine the chemical activity or the fugacity of the contaminant in the tissue (Wilcockson and Gobas 2001; Ossiander et al. 2008; Jahnke et al. 2009; Mayer et al. 2009) Diffusive sampling techniques such as SPME (Heringa et al. 2003) and microdialysis (Oravcova et al. 1996) can be applied to measure freely dissolved concentrations in, for example, digestive fluids and blood, which can be considered effective concentrations for internal diffusion and partitioning processes. Information about the concentration of unbound chemical (freely dissolved) is relevant as dose metrics in in vitro tests (Heringa et al. 2004), as well as in the extrapolation from in vitro biotransformation to in vivo biotransformation (Riley et al. 2005).

Biomimetic devices provide a useful range of applicability to compounds that are not biotransformed and reach steady state during the exposure time of toxicity test. They fail for those toxicants that are metabolized and those that exhibit large variation in uptake rate across species and when uptake is not yet in steady state at time of death (or effect).

\section{Chemical activity and fugacity as new internal exposure parameters}

Internal exposure is generally expressed and understood as a contaminant concentration. Alternatively, internal exposure might also be expressed as fugacity or the unitless chemical activity. The former expresses the escaping tendency of a chemical into ideal gas, whereas the latter expresses the energetic state of a chemical relative to its pure (sub)cooled liquid. Both parameters are multimedia parameters that have been applied in environmental fate modeling (Mackay 2004, and references cited therein) as well as in bioavailability and toxicological studies (Ferguson, 1939; Mayer and Reichenberg, 2006; Mackay et al. 2009). The strength of these parameters within an exposure context is that the partitioning of a pollutant into an organism as well as its intra-tissue diffusion is always directed from high to low chemical activity and fugacity. Equilibrium partitioning is characterized by uniform fugacity and chemical activity. This gives very good possibilities for the study and prediction of internal exposure and exposure at the target site. Such predictions are limited to situations where biotransformation is not an issue or biotransformation rates are known. However, actual measurements of internal chemical activities can then be applied to support or challenge such predictions and also to establish the link between internal chemical activities and a toxic response.

Chemical activity is also advantageous for describing baseline toxicity, which occurs at relatively constant values ranging between 0.01 and 0.1 (Mayer et al. 2006; Reichenberg and Mayer 2006). Chemical activity and fugacity can be measured with various types of equilibrium sampling devices (Mayer et al. 2003; Jahnke et al. 2009), such as SPME fibers (Legind et al. 2007; Ossiander et al. 2008), silicone microtubings (Mayer et al. 2009), and thinly coated glass slide or vials (Wilcockson and Gobas 2001; Reichenberg et al. 2008; Golding et al. 2007). The potential of equilibrium sampling devices for the measurement of internal exposure is an area of ongoing research. 


\section{ROLE OF BIOTRANSFORMATION}

For those organic compounds, such as organophosphates, DDT, polychlorinated biphenyls, and organotins, that exhibit specific MoOAs and are metabolized, biotransformation and metabolite concentrations are an important issue. Biotransformation of chemicals can lead to either detoxification or the induction (i.e., increased toxicity) of toxic metabolites (e.g., benzene transformed to an epoxide by mixed-function oxygenases [MFO]). Until now, the TRA for metabolized compounds showing specific toxicity has not been fully developed, because it is sometimes difficult to obtain a separate measurement of a parent compound and its metabolites. This reflects the general lack of ecotoxicological work that has examined metabolites. However, as shown in Figure 7 , not only may metabolism affect the toxicokinetics, but the metabolites may also contribute to the toxic effect at the same or different target site, i.e., through the same or different mechanisms of toxicity.

Work conducted by Nuutinen et al. (2003) examined the uptake, biotransformation, and elimination rates of pentachlorophenol, methyl parathion, fluoranthene, and hexachlorbiphenyl, as well as their metabolites, in Hyalella azteca. These investigators found that $H$. azteca can metabolize a variety of chemicals with different modes of action and that the elimination rates of the metabolites could be considerably lower than the parent compound and this led to substantial accumulation of the metabolites. These investigators argued that if the TRA is to be a "truly effective dose metric," it needs to consider the effects caused by metabolites. By not including the IEC values for metabolites all current IEC values are either correct (in the case of no biotransformation) or currently underestimate the true value (in the case of biotransformation occurring). However, the extent of the underestimation of the true IEC is currently unknown and will vary depending on the extent of biotransformation and the toxicity of the metabolites.

For the TRA to predict toxic effects of metabolizable chemicals, improvement is needed in 1) predicting whether chemicals can be biotransformed; 2) determining the

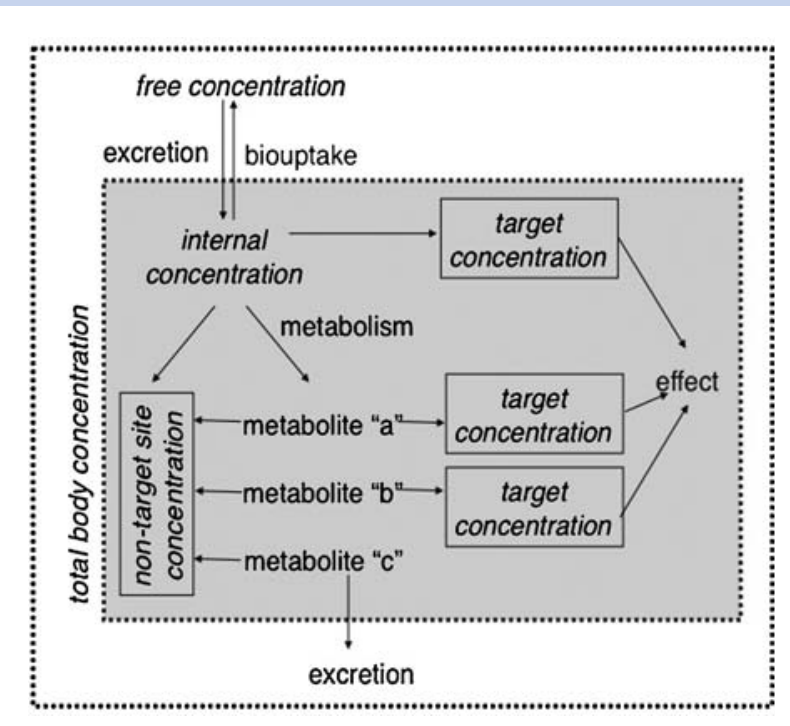

Figure 7. Extension of Figure 1 for the conditions that metabolites formed during toxicokinetic phase contribute to toxicity. metabolites' contribution in a mixture of parent chemicals and metabolites to the observed toxicity; and 3) determining or predicting the biological half-life of the metabolites (Fenner et al. 2002; Lienert et al. 2007).

If a chemical can be biotransformed, it means that within the test organism, even when it is exposed to a single chemical externally, the toxicity is actually caused by a mixture of the parent compound and the metabolite(s), provided the metabolite is toxic. Pioneering work to incorporate this concept into toxicokinetic and toxicodynamic modeling has been undertaken in a series of articles by Lee and Landrum (2006a, 2006b). These investigators reported that the toxic effects of metabolized polycyclic aromatic hydrocarbon (PAHs) can be assessed as a "dynamic" mixture of the parent compound and metabolites with different toxicokinetics and toxicodynamics (Lee and Landrum 2006a). The toxicokinetics and time-dependent toxicity of parent compound and metabolites for pyrene and fluorene in $H$. azteca were separately determined in toxicity and toxicokinetic experiments for parent compound in the presence and absence of a biotransformation inhibitor. Both metabolites are eliminated more slowly than the parent compounds; the metabolites of pyrene are nontoxic, but those of fluorene are toxic.

\section{TOXICOKINETIC MODELING: FROM EXTERNAL EXPOSURE TO INTERNAL AND TARGET RESIDUES}

In most cases, target site concentrations are not experimentally accessible; therefore, we need models to predict them, which can be done using TK models. Toxicokinetics can be used to determine the concentration at the target site by quantifying the processes of uptake and elimination (passive diffusion, excretion, and metabolism).

The most direct exposure parameter for toxicological effects is the dose at the target site, or what Paustenbach (2000) refers to as the biologically effective dose (BED). Measurement of the dose at the target site is not feasible, however, necessitating kinetic models with which to predict the target dose. These toxicokinetic models include processes such as uptake, biotransformation, internal distribution between tissues, and excretion (Figure 8). One also has to consider the distribution of a chemical among several phases within a tissue, such as the freely dissolved fraction and the fraction bound to serum proteins, membranes, lipids, cellular proteins, and receptors. Tissue-specific or organ-specific residues are one step closer to the dose at the target site, hence potency differences that are simply related to a difference in absorption, internal distribution, metabolism, or excretion can then be ruled out. Two kinds of BED are considered in ecotoxicology. One is the concentration at the target site, and the other is receptor occupancy (percentage of occupied receptors) (Figure 8). The choice of the appropriate BED depends on the mechanism of toxicity of the toxicant of interest.

In ecotoxicology, kinetic models are often simple firstorder, 1-compartment models in which the organism is considered as 1 homogeneous compartment (e.g., Nuutinen et al. 2003; Ashauer, Caravatti, et al. 2010). In this example, the whole-body tissue concentration acts as a surrogate for the concentration at the target site because they are often proportional. The time course can be described with the single first-order 1-compartment model in which the uptake rate is proportional to the toxicant concentration in the surrounding media and the elimination (depuration) rate is 


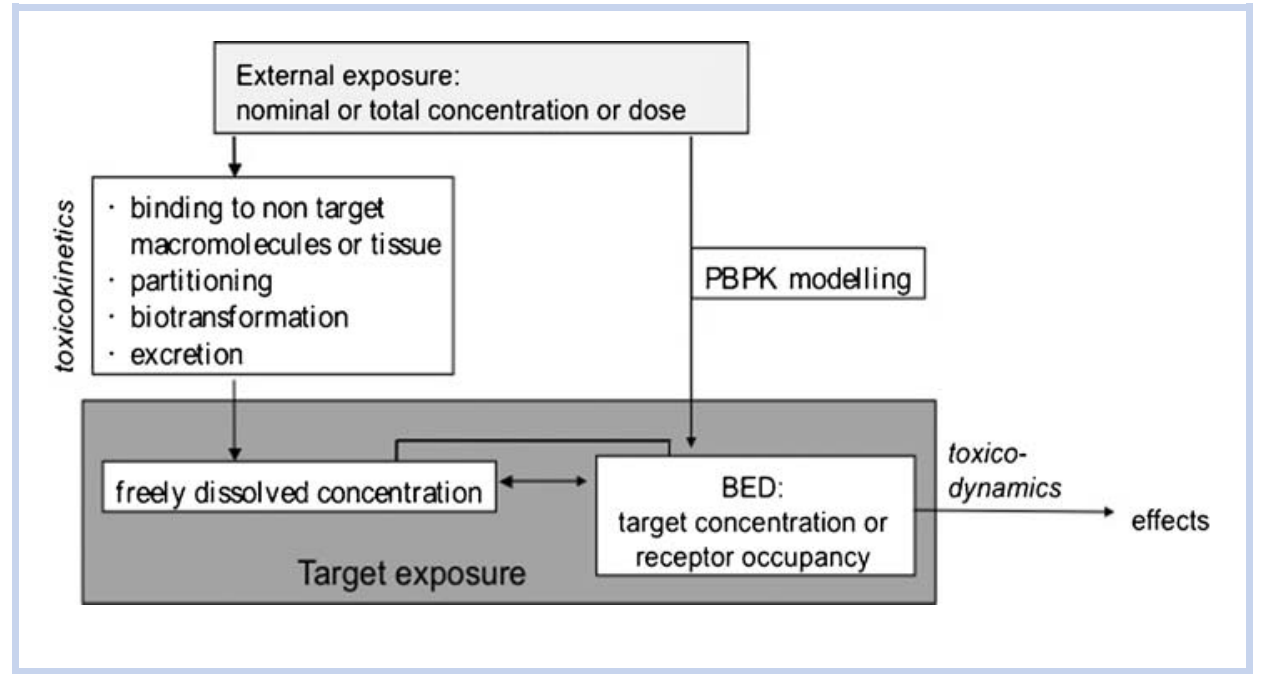

Figure 8. Relationship between the different dose metrics and applicability of TK models and PBPK modeling.

proportional to the toxicant concentration in the organisms,

$$
\frac{d \mathrm{C}_{\text {int }}(t)}{d t}=k_{\text {in }} \times \mathrm{C}(t)-k_{\text {out }} \times \mathrm{C}_{\text {int }}(t)
$$

where $\mathrm{C}_{\text {int }}$ is the internal concentration [amount $\times$ mass $^{-1}$ ], C the concentration in the water [amount $\times$ volume $\left.e^{-1}\right]$, and $k_{\text {in }}$ and $k_{\text {out }}$ the uptake rate constant [volume $\times$ mass $^{-1} \times$ time $^{-1}$ ] and the elimination rate constant $\left[\right.$ time $\left.^{-1}\right]$, respectively (amount is defined as amount of toxicant, units in mol, mass refers to the mass of the organism, typically given as $g_{\text {wet weight }}$ ).

In this simplified model, the process "elimination" lumps all processes related to excretion, metabolism, dilution by growth, and other factors into a single rate constant, resulting in simple first-order, 1-compartment model where the organism is considered as 1 homogeneous compartment. The simple first-order kinetics hold only as long as growth is zero (slow-growing organisms) or when growth is exponential over the course of the experiment. Otherwise the model is more complex (Kooijman et al. 1996). The TK parameters can be measured in bioconcentration experiments independent of toxic effect measurements in toxicity tests. Prediction intervals around internal concentrations and bioaccumulation factors can also be calculated (Lin et al. 2004; Ashauer, Caravatti, et al. 2010).

This might be sufficient for small organisms, like daphnids and copepods, but further refinement is possible (and necessary) for larger organisms such as fish. Even for the simple 1-compartment models, however, additional compartments can be included for specific processes such as metabolism (Nuutinen et al. 2003; Ashauer, Hintermeister, et al. 2010). Multicompartment models that include storage lipids and other compartments but that are not physiologically based are another approach. Modeling and prediction of dose at the level of a tissue require more sophisticated kinetic modeling such as physiologically based pharmacokinetic modeling (PBPK). Physiological parameters such as blood flow and volume of distribution are incorporated in these models to make them more realistic. PBPK models designed for comparison of the toxicological dose of chemicals with a certain mode of action at the level of a specific tissue, ideally the target site (Figure 8). PBPK modeling is also a strong tool in extrapolation among different exposure routes and can easily handle multiple uptake routes (Andersen et al. 1995; Yang et al. 1998; Andersen et al. 1999). These models also allow one to extrapolate back from a tissue or target dose to a dose in environmental compartments (water, food, soil, and sediment) in a way similar to that used in food chain models.

The application of PBPK models in ecotoxicology is limited to kinetic modeling in larger fish such as the rainbow trout (Nichols et al. 1991, 2004). For example, Nichols et al. (2004) developed a PBPK model for dietary uptake of hydrophobic chemicals by fish and applied this same model to simulate the effects of biotransformation on internal body residues. Figure 9 presents a simplified scheme of the compartments and processes of such a PBPK for fish. PBPK

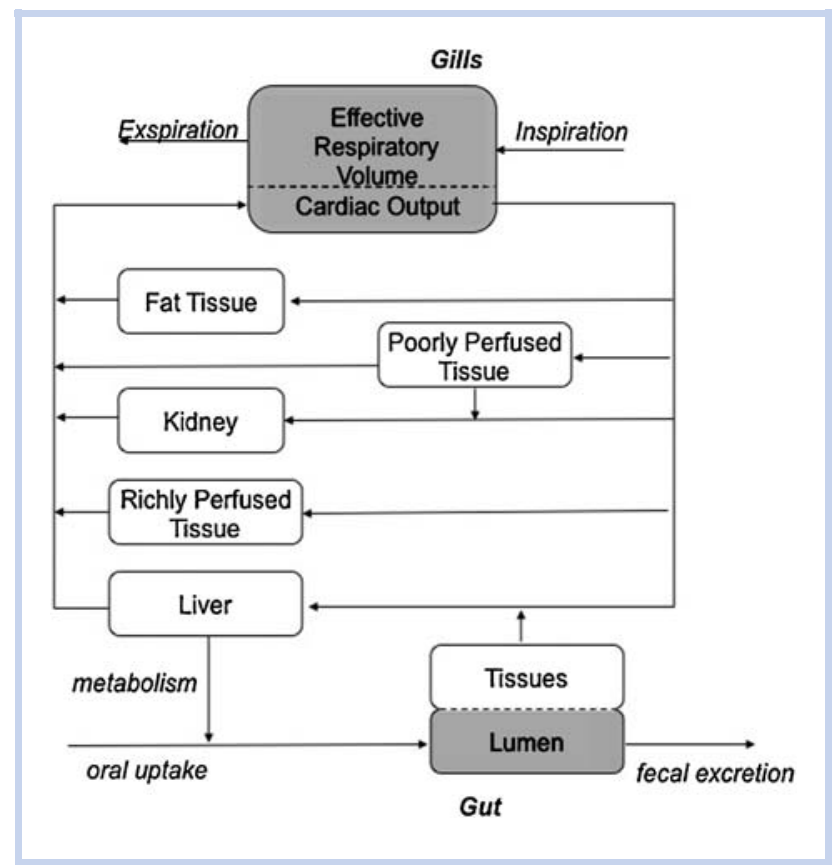

Figure 9. Simplified scheme of a PBPK model for fish. Adapted and reprinted with permission from Toxicol Sci 77:206-218. Copyright 2004 Oxford University Press. 
modeling may also be applied to translate and extrapolate toxicity among different organisms. De Jongh et al. (1998) analyzed toxicity data for rat from inhalation studies via a PBPK model and compared the internal effect doses with data from fish studies. The predicted internal effect concentrations for nonreactive volatile organic compounds (baseline toxicants) were remarkably similar.

\section{TOXICODYNAMIC MODELING}

How organisms react as a result of exposure to toxicants is a crucial component of ecotoxicology. Two alternate views are used: a deterministic (individual tolerance distribution) and a stochastic (hazard model) approach. It is important to understand these alternate views, as both are used by various TK-TD models and are crucial to "predicting consequences to populations after repeated or chronic exposure to any particular toxicant" (Newman and McCloskey, 2000; Zhao and Newman 2007; Ashauer 2010). The deterministic approach, or individual tolerance distribution concept, assumes that each individual has its own unique tolerance to a toxicant and that when this is exceeded that individual will exhibit toxic effects (e.g., die). In contrast, the stochastic approach states that each individual has the same probability of suffering a toxic effect at a given toxicant concentration. The apparently subtle differences in these approaches may lead to different outcomes. Consider a scenario in which a population was exposed to a sufficiently high concentration of a toxicant that $50 \%$ died and the survivors were then exposed to no toxicant for sufficient time to permit recovery. Following this, the survivors were exposed to the same concentration of toxicant for the same duration. Under the deterministic approach, there would be no subsequent deaths because survivors previously tolerated that concentration. In contrast, under the stochastic approach, 50\% of the survivors from the previous exposure would die, and this would continue to occur with subsequent exposures. Experiments by Heagler et al. (1994) and Newman and McCloskey (2000) revealed that neither approach fully explains the results; rather, it appeared that the deterministic approach held at low concentrations whereas the stochastic held at high exposure concentrations. Recently, a theoretical study demonstrated that a TK-TD modeling approach in which TK-TD parameters are allowed to vary among individuals in a natural or experimental population could reproduce key characteristics of both concepts (Ashauer 2010). This finding suggests that survival of an individual organism can be characterized using the hazard model approach (stochastic), and the whole set of TK-TD parameters for an organism represents "individual tolerance." The distribution of individual tolerances in a population (deterministic approach) is then represented by the distribution of TK-TD parameters among individuals (Ashauer 2010).

The deterministic approach predicts that organisms die immediately once they reach their ILC50. Hence in long-term experiments those organisms that have reached the ILC50 die as soon as this internal concentration is reached, whereas the others that have not reached the ILC50 survive. This observation is explained traditionally by assuming a distribution of individual tolerances within that population. Those individuals that have a tolerance that is lower than the ILC50 will die and those with a higher tolerance will survive, even after long periods of exposure. Therefore, the population composition shifts toward more tolerant individuals. An example is the pulsed $\mathrm{Cu}$ exposure to Pimephales promelas and Daphnia magna observed by Butcher et al. (2006). However, what exactly the "individual tolerance" represents, or what dimensions it should have, is not clearly defined. Furthermore, the shift of the population toward less sensitive organisms, as well as the phenomenon of "more sensitive" individuals dying and "less sensitive" individuals not dying, can be explained using a hazard modeling framework in which TK-TD parameters vary among individuals (Ashauer 2010).

Hazard models assume that death is stochastic. The hazard rate is the probability of an organism dying at a given point in time. If, under constant exposure conditions, the hazard rate is greater than zero, i.e., at least some organisms die, which means that during constant exposure the hazard rate remains constant at this value greater than zero, eventually all organisms will die if the exposure duration is long enough. One must keep in mind that these are models of limiting cases and biological reality may often lie somewhere in between.

Toxicodynamic models are generally linked to toxicokinetic models and have internal concentrations as a function of time as input parameters. They describe the dynamics of injury and recovery in the organism and relate them to the observed effects. The simplest mathematical description of toxicodynamics uses a first-order process to describe the accrual of injury, quantified by the generic measure "damage" (first used by Ankley et al. 1995), and the repair or recovery of damage (Figure 10). The rate of accrual of damage is proportional to the rate of accumulation of the toxicant at the target site and the recovery of damage is proportional to the amount of damage present, as shown in the following equation:

$$
\frac{d D(t)}{d t}=k_{\mathrm{k}} \times C_{\mathrm{int}}(t)-k_{\mathrm{r}} \times D(t)
$$

In Eqn. $4, k_{\mathrm{k}}$ is a killing rate constant [mass $\times$ amount $^{-1} \times$ time $\left.^{-1}\right], k_{\mathrm{r}}$ is the rate constant for damage recovery or repair [time $\left.{ }^{-1}\right]$ and $D(t)$ is damage [-].

One of the underlying assumptions of the TD model described with Eqn. 4 is that the concentration at the target site is so low that it does not lead to saturation of the receptors at the target site. For specific mechanisms of action, e.g., those for organophosphorus insecticides, the model can be reformulated to include a limited number of receptors, and the damage would then be expressed as a fraction of occupied receptors (Jager et al. 2005).

The processes that affect damage take place at a suborganism scale. Not all damage necessarily leads to effects that are observable at the scale of the organism, just as there may be concentrations of the toxicant in the organism that do not result in any effect on the organism. Hence this link, especially for the endpoint survival, often requires a threshold of effect (Bedaux et al. 1994; Jager et al. 2005; Ashauer et al. 2007a, 2007b; Ashauer and Brown 2008, Ashauer, Hintermeister et al. 2010). Threshold values are considered purely fit parameters, but their mechanistic meaning remains to be investigated.

Examples of stochastic hazard TK-TD models are the DEBtox approach (Bedaux et al. 1994; Kooijman et al. 1996; Péry et al. 2001), more recently the receptor kinetics model developed by Jager and Kooijman (2005) and the threshold 


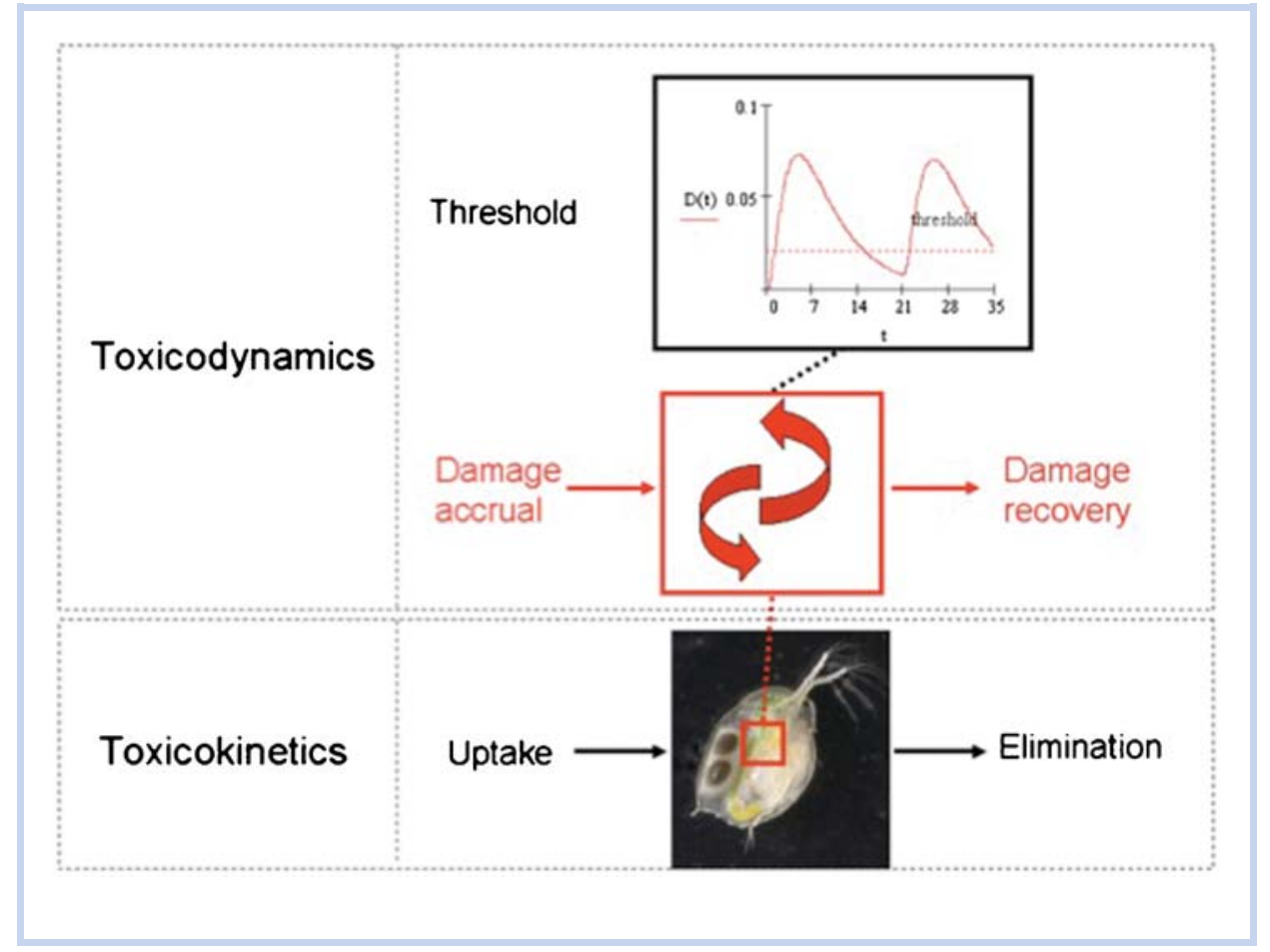

Figure 10. Conceptual framework of toxicokinetic-dynamic models.

damage model (TDM) (all reviewed in Ashauer and Brown 2008). The damage assessment model (DAM) is a deterministic toxicity model based on the individual tolerance distribution (Lee et al. 2002; 2003). The TDM can deal with fluctuating and pulsed exposure to single and multiple contaminants (Ashauer et al. 2007a, 2007b; Ashauer et al. 2010b); the DAM has already been applied to model the mixture effect of internal metabolites formed (Lee and Landrum 2006a; 2006b).

\section{Relationship between mechanism of action and TK-TD models}

Some TK-TD models can accommodate any speed of reversibility (DAM, receptor model, and TDM), whereas others are only applicable to modes of action that show instantaneous recovery (CBR, DEBtox) or irreversible damage (AUC, CAUC). Table 3 provides an overview of the discussed models and for which types of toxic mechanisms they can be applied (see review of Ashauer and Brown 2008).

The model assumptions listed in Table 3 provide a first step of guidance as to which models are best suited for which mechanism of action. In general, selecting the appropriate model is aided by considering 2 kinds of biologically effective dose for toxicity: 1) tissue residue at target sites, and 2) receptor occupancy. Information on the mechanism of action for a toxicant gives a guidance to choose a toxicity model using tissue residue or receptor occupancy.

\section{In vitro data to support TK-TD modeling}

The application of PBPK modeling requires data on tissueblood partition coefficients as well as biotransformation rates. Kinetic parameters, including biotransformation rates from experiments with isolated cells or microsomes, are often measured or estimated from in vitro data. However, these data require a correction for differences in protein binding between the in vitro and in vivo situation (Houston 1994; Obach 1997; Riley et al. 2005).

Effect data from in vitro tests may play a role in predicting in vivo responses through toxicodynamic modeling. One should also be aware of potential pitfalls in these extrapolations. First, in vitro data are often based on nominal concentrations, and such data are not reliable because actual concentrations in the in vitro test may be far below the nominal concentration. Another complicating factor is the presence of serum proteins that will bind chemicals, especially the hydrophobic ones. For quantifying toxic effects, only the unbound fraction of a chemical is relevant. These phenomena lead to high variability in the outcome of in vitro tests because the test conditions are not always comparable (Gülden et al. 1994; Vaes et al. 1996; Gülden et al. 1997; Nagel et al. 1998; Heringa 2004). As an alternative to total concentrations, several investigators have proposed using the concentration of the unbound chemical (Gülden et al. 1994; Vaes et al. 1996; Heringa 2004), internal cellular, or cell membrane concentrations (Escher and Schwarzenbach 2002) as dose parameters because they represent the intrinsic activity of a chemical. Very recent research suggests that freely dissolved concentrations or chemical activities in such in vitro tests can be controlled and maintained constant by partitioning from a chemically loaded polymer (Bandow et al. 2009; Kwon et al. 2009; Smith et al. 2010). This technique is expected to facilitate the extrapolation of in vitro data to environmentally relevant in vivo responses.

\section{Mixture toxicity modeling in toxicokinetic-toxicodynamic models}

How compounds behave in mixtures depends on their target site and their mode of action (Dyer et al. 2011). If they 


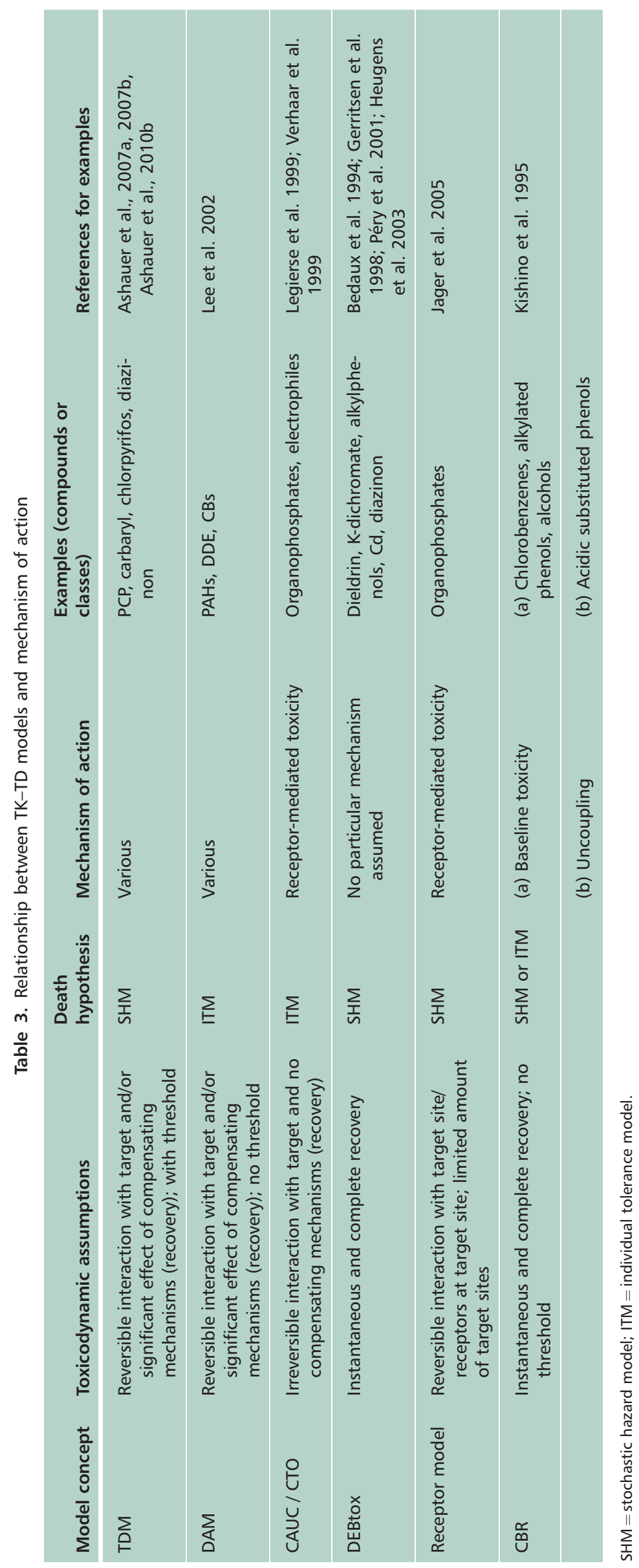


act at the same target site and have the same MoOA, they act together according to the concept of "concentration addition" (CA). If they have different target sites and do not interact (also not in the toxicokinetic phase), their toxicity can be predicted by the mixture toxicity concept of "independent action" (IA) (also termed "response addition") (Dyer et al. 2011). If there are interactions in the toxicokinetic phase or at the target site, synergism and antagonism may potentially occur. In other words, deviation from the CA or IA models can be explained by toxicokinetic and/or toxicodynamic interactions among components in a mixture (Dyer et al. 2011).

In mixtures, toxicokinetic interactions involve the alteration of metabolism and disposition of 1 compound by another. These interactions can be mediated by the induction or inhibition of the activation or detoxification step. Toxicodynamic interactions include those processes that do not directly affect the metabolism or disposition of a xenobiotic but that affect a tissue's response or susceptibility to toxic injury. These interactions include depletion or induction of cytoprotective factors, such as a reduction of glutathione (Freidig et al. 2001) and alterations in tissue repair. A very unusual example is the formation of a mixed heterodimer in protonophoric uncoupling that has a more potent intrinsic activity than the 2 mixture components acting independently (Escher et al. 2001).

The contribution of a compound to the mixture toxicity is expressed in toxic units $\mathrm{TU}_{i}$, defined as the ratio of concentration of mixture component $i$ to its effect concentration ECp, expressed in either external or internal concentration units, $\mathrm{TU}_{i}=\mathrm{C}_{i} / \mathrm{EC}_{\mathrm{p} i}$ or $\mathrm{TU}_{i}=\mathrm{IC}_{i} / \mathrm{IEC}_{\mathrm{p} i}$. Under the condition of constant exposure conditions, the relationship between TUs is as follows.

- If critical body residues are time dependent, toxic units based on body residue as well as those based on external concentrations are also time dependent.

- In a mixture without toxicological interactions, but with time-dependent toxicity, there is no difference between the time-dependent TU concept based on external concentrations or body residues (Lee and Landrum 2006b).

- In a mixture with toxic interactions and time-dependent toxicity where there are toxicokinetic or toxicodynamic interactions, e.g., competition among different metals binding to the same ligand or biotransformation inhibition and/or induction for organic compounds, the TU values based on body residues are not comparable to TU values based on external concentrations.

If there are no toxicodynamic interactions within a mixture then the concept of "Damage Addition" (DA) can be used in toxicokinetic and toxicodynamic mixture models (Lee and Landrum 2006b). In this concept the sum of damages from the individual compounds $i$ yields the total damage for the mixture:

$$
D_{\text {mix }}(t)=\sum_{t} D_{i}(t)
$$

The DA concept within the DAM can be applied to a mixture containing compounds with and without toxicokinetic interaction. In both cases, the DA model is equivalent to the CA model (Lee and Landrum 2006b).
Not only are there mixtures of different compounds, but the formation of metabolites in the body and the resulting mixture toxicity of parent and metabolite can be looked at as a mixture effect. Interpreting the metabolites' contribution to the observed toxicity is feasible within the body residue approach and could be improved by better predictions of biotransformation. The toxic effects of readily metabolized compounds such as PAHs could be assessed as a mixture of the parent compound and its metabolites with different toxicokinetics and toxicodynamics (Lee and Landrum 2006b). Furthermore, the DEBtox survival model was applied to predict the effects of mixtures of heavy metals in time (Baas et al. 2007).

\section{Sequential exposure resulting in mixture effects}

Exposure of aquatic organisms to contaminants may occur in repeated sequential pulses (Reinert et al. 2002). Hence organisms may be exposed to multiple toxicants after each other. This sequential exposure to multiple compounds requires a mixture toxicity model that explicitly addresses the time course of the toxicant concentration in the organism, i.e., toxicokinetics, as well as the time course of organism recovery. The TDM provides such a framework and was recently extended (TDMmix) to address sequential exposure to multiple compounds (sequential mixtures; Ashauer et al. 2007a). The TDMmix also applies the concept of damage addition. The sequence of exposure to multiple toxicants was observed to matter, i.e., that mortality between treatments differed significantly as a function of order of exposure. This observation was predicted by the TDMmix model and explained by the different speed of recovery for the 2 compounds.

\section{Delayed toxicity and time-dependent effect after steady state}

In many cases, lethal body residue is not constant, even after toxicokinetic steady state is obtained. These observations can be explained if toxicodynamics are considered as a second step that has a time dependence, i.e., a kinetic connotation. When the body residues attain steady state, critical body residues can be constant (constant CBR model), or decrease with time (CAUC model, DEBtox model), or decrease and reach the incipient value (DAM), depending on the damage recovery rate. The lethal body residue in constant exposure tests depends on the damage recovery rate as well as the duration of exposure resulting from the buildup of damage in the organism with longer-term exposures.

Delayed effects and recovery after exposure are determined by toxicokinetic and toxicodynamic processes, which control the velocity of toxicant bioaccumulation, the velocity of the injury process, and the degree of the reversibility of the toxic effect (Mancini 1983; Breck 1988; Hickie et al. 1995; Péry et al. 2001; Pieters et al. 2006). Therefore, the magnitude and time course of delayed effects depend on factors such as exposure time, exposure concentration, toxicokinetics, mode of toxic action, and measurement endpoints, including lethal or sublethal endpoints such as immobility, growth, and enzyme activity. Delayed toxicity, i.e., effects after the exposure period, has been reported, for example, for herbicides (Cedergreen et al. 2005), Cu (Zhao et al. 2004), and chlorpyrifos mortality (Van der Hoeven and Gerritsen 1997; Naddy et al. 2000; Naddy and Klaine 2001, Ashauer 
et al. 2007a, 2007c). Addressing delayed effects is particularly relevant for the risk assessment of intermittent exposure event or fluctuating concentrations (Reinert et al. 2002; Ashauer et al. 2006). Application of toxicokinetic and toxicodynamic models to time-varying exposure conditions facilitates the understanding of the underlying processes for delayed toxicity; it also provides a predictive tool. For example, increased mortality from subsequent pulses of chlorpyrifos or diazinon to Gammarus pulex, 2 weeks after the first pulse, could be attributed to toxicodynamic processes (Ashauer et al. 2007a; Ashauer et al. 2010b). Buildup of internal concentrations could be excluded, based on previous measurements of internal concentrations and toxicokinetic simulation.

\section{RECOMMENDATIONS FOR FUTURE RESEARCH}

Target site concentration or critical reaction rates with the target are useful measures to unify the description of toxicity between different species, chemicals, and exposure regimes. As this review has demonstrated, even for the "simple" mechanism of baseline toxicity, whole-body tissue residues are not necessarily sufficient surrogates of the target site concentration. In practice, it is difficult and in many cases impossible to determine target site concentrations experimentally; therefore, we should continue to focus on measuring whole-body tissue residues for small organisms and target organ tissue residues for larger animals but try to complement the measurements by additional information like lipid content and protein content determination to facilitate modeling of target site concentrations. The present work reviews the latest advances in equilibrium partitioning for simpler experimental approximation of tissue residues.

In addition, we advocate the use of TK/TD modeling as a tool to refine the tissue residue approach. Variability in the toxicity of different toxicants is due to the toxicant characteristics. Some physicochemical characteristics affect the toxicokinetics, whereas others modify the toxicodynamics. In contrast, the variability in species sensitivity to toxicants could be attributed to species-specific traits. Some trait differences may be important for toxicokinetics, whereas others may be relevant for toxicodynamics. Hence, explicit process understanding and modeling of toxicokinetics and toxicodynamics may facilitate a more complete understanding of the variability inherent in ecotoxicological data and processes.

Specific recommendations for further research include the following:

- Further testing and validation of equilibrium sampling devices and diffusive sampler techniques to measure or estimate internal dose as well as chemical activity as a more unifying dose metric

- Exploring alternative empirical parameters as a measure for the effects of specific acting chemicals

- Refinement of the body residue concept by measuring tissue-based residues and the application of kinetic modeling in analyzing these tissue-based residues

- Including alternative measured descriptors such as critical depletion rates in TK-TD models

- Seeking further insight into the role of metabolism on body, or tissue, residue-based interpretation of toxicological effects
Acknowledgment-The authors thank the numerous sponsors for their generous financial contributions that supported this workshop. We thank Thomas Preuss and Tjalling Jager for helpful discussions; Theo Traas and Jan Hendriks for providing data compilations published in (Hendriks et al. 2005); and Lynn McCarty, Nancy Beckvar, Peter Landrum, Stuart Simpson, Jenny Stauber, and Jan Hendriks for helpful comments on the manuscript. The opinions and views expressed in this paper are those of the authors and do not necessarily reflect views and policies of their affiliated institutions.

\section{REFERENCES}

Abernethy SG, Mackay D, McCarty LS. 1988. "Volume fraction" correlation for narcosis in aquatic organisms: The key role of partitioning. Environ Toxicol Chem 7:469-481.

Alda Alvarez O, Jager T, Redondo EM, Kammenga JE. 2006. Physiological modes of action of toxic chemicals in the nematode Acrobeloides nanus. Environ Toxicol Chem 25:3230-3237.

Amdur M, Doull J, Klaassen C, editors. 1991. Cassarett and Doull's toxicology. The basic science of poisons 4th ed. New York (NY): Pergamon. $1033 \mathrm{p}$.

Andersen ME, Clewell H Jr, Frederick CB. 1995. Applying simulation modelling to problems in toxicology and risk assessment-a short perspective. Toxicol Appl Pharmacol 133:181-187.

Andersen ME, Conolly RB, Fausman KEM, Ziese L. 1999. Quantitative mechanistically based dose-response modeling with endocrine-active compounds. Environ Health Persp 107 (Suppl 4): 631-638.

Ankley GT, Erickson RJ, Phipps GL, Mattson VR, Kosian PA, Sheedy BR, Cox JS. 1995. Effects of light-intensity on the phototoxicity of fluoranthene to a benthic macroinvertebrate. Environ Sci Technol 29:2828-2833.

Ankley GT, Bennett RS, Erickson RJ, Hoff DJ, Hornung MW, Johnson RD, Mount DR, Nichols JW, Russom CL, Schmieder PK, Serrrano JA, Tietge JE, Villeneuve DL. 2010. Adverse outcome pathways: A conceptual framework to support ecotoxicology research and risk assessment. Environ Toxicol Chem 29:730-741.

Antkowiak B. 2001. How do general anaesthetics work? Naturwissenschaften 88:201-213.

Ashauer R. 2010. Toxicokinetic-toxicodynamic modelling in an individual based context-consequences of parameter variability. Ecol Modell 221:1325-1328.

Ashauer R, Brown CD. 2008. Toxicodynamics assumptions in ecotoxicological models. Environ Chem Toxicol 27:1817-1821.

Ashauer R, Boxall ABA, Brown CD. 2006. Predicting effects on aquatic organisms from fluctuating or pulsed exposure to pesticides. Environ Toxicol Chem 25:1899-1912.

Ashauer R, Boxall ABA, Brown CD. 2007a. New ecotoxicological model to simulate survival of aquatic invertebrates after exposure to fluctuating and sequential pulses of pesticides. Environ Sci Technol 41:1480-1486.

Ashauer R, Boxall ABA, Brown CD. 2007b. Simulating toxicity of carbaryl to Gammarus pulex after sequential pulsed exposure. Environ Sci Technol 41:5528-5534.

Ashauer R, Caravatti I, Hintermeister A, Escher BI. 2010a. Bioaccumulation kinetics of organic xenobiotic pollutants in the freshwater invertebrate Gammarus pulex modelled with prediction intervals. Environ Toxicol Chem 29:1625-1636.

Ashauer R, Hintermeister A, Caravatti I, Kretschmann A, Escher BI. 2010b. Carryover toxicity from exposure to diazinon is explained by toxicokinetictoxicodynamic modeling of biotransformation and slow organism recovery. Environ Sci Technol 44:3963-3971.

Baas J, Van Houte BPP, Van Gestel CAM, Kooijman SALM. 2007. Modelling the effects of binary mixtures on survival in time. Environ Toxicol Chem 26:1320 1327.

Bandow N, Altenburger R, Lübcke-von Varel U, Paschke A, Streck G, Brack W. 2009 Partitioning-based dosing: An approach to include bioavailability in the effectdirected analysis of contaminated samples. Environ Sci Technol 43:3891-3896.

Barron MG, Hansen J, Lipton J. 2002. Association between contaminant tissue residues and effects in aquatic animals. Rev Environ Contam Toxicol 173:1-37.

Bedaux JJM, Kooijman SALM. 1994. Statistical analysis of bioassays based on hazard modelling. Environ Ecol Stat 1:303-314. 
Bradbury SP. 1994. Predicting modes of toxic action from chemical structure. An overview. SAR QSAR Environ Res 2:89-104.

Breck JE. 1988. Relationships among models for acute toxicity effects: Application to fluctuating concentrations. Environ Toxicol Chem 7:775-778.

Butcher J, Diamon J, Bearr J, Latimer H, Klaine S, Hoang T, Bowersox M. 2006. Toxicity models of pulsed copper exposure to Pimephales promelas and Daphnia magna. Environ Toxicol Chem 25:2541-2550.

Cedergreen N, Andersen L, Olesen CF, Spliid HH, Streibig JC. 2005. Does the effect of herbicide pulse exposure on aquatic plants depend on $\mathrm{K}_{\mathrm{ow}}$ or mode of action? Aquat Toxicol 71:261-271.

Chaisuksant Y, Yu QM, Connell D. 1997. Internal lethal concentrations of halobenzenes with fish (Gambusia affinis). Ecotoxicol Environ Saf 37:66-75.

Chaisuksant Y, Yu QM, Connell DW. 1999. The internal critical level concept of nonspecific toxicity. Rev Environ Contam Toxicol 162:1-41.

Collins F, Gray GN, Bucher JR. 2008. Transforming environmental health protection. Science 319:906-907.

De Bruyn A, Gobas F. 2007. The sorptive capacity of animal protein. Environ Toxicol Chem 26:1803-1808.

de Jongh J, Verhaar HJM, Hermens JLM. 1998. Role of kinetics in acute lethality of nonreactive volatile organic compounds (VOCs). Toxicol Sci 45:26-32.

Deneer JW, Seinen W, Hermens JLM. 1988. The acute toxicity of aldehydes to the guppy. Aquat Toxicol 12:185-192.

Deneer JW, Sinnige TL, Seinen W, Hermens JLM. 1988. A quantitative structureactivity relationship for the acute toxicity of some epoxy compounds to the guppy. Aquat Toxicol 13:195-204.

Drummond RA, Russom CL. 1990. Behavioral toxicity syndromes-a promising tool for assessing toxicity mechanisms in juvenile fathead minnows. Environ Toxicol Chem 9:37-46.

Dyer S, Warne MSJ, Meyer JS, Leslie HA, Escher BI. 2011. The tissue residue approach for chemical mixtures. Integr Environ Assess Manag 7:99-115.

Escher BI, Hermens JLM. 2002. Modes of action in ecotoxicology: Their role in body burdens, species sensitivity, QSARs, and mixture effects. Environ Sci Technol 36:4201-4217.

Escher B, Schwarzenbach RP. 2002. Mechanistic studies on baseline toxicity and uncoupling as a basis for modeling internal lethal concentrations in aquatic organisms. Aquat Sci 64:20-35.

Escher BI, Hermens JLM. 2004. Internal exposure_linking bioavailability to effects. Environ Sci Technol 38:455A-462A.

Escher BI, Hunziker R, Westall JC, Schwarzenbach RP. 1999. Kinetic model to describe the intrinsic uncoupling activity of substituted phenols in energy transducing membranes. Environ Sci Technol 33:560-570.

Escher Bl, Hunziker RW, Schwarzenbach RP. 2001. Interaction of phenolic uncouplers in binary mixtures: Concentration-additive and synergistic effects. Environ Sci Technol 35:3905-3914.

Escher BI, Eggen RIL, Schreiber U, Schreiber Z, Vye E, Wisner B, Schwarzenbach RP. 2002. Baseline toxicity (narcosis) of organic chemicals determined by membrane potential measurements in energy-transducing membranes. Environ Sci Technol 36:1971-1979.

Fenner K, Kooijman C, Scheringer M, Hungerbuhler K. 2002. Including transformation products into the risk assessment for chemicals: The case of nonylphenol ethoxylate usage in Switzerland. Environ Sci Technol 36:11471154.

Ferguson J. 1939. The use of chemical potentials as indices of toxicity. Proc $R$ Soc Lond Ser B Biol Sci 127:387-404.

Franks NP, Lieb WR. 1990. Mechanisms of general anaesthesia. Environ Health Persp 87:199-205.

Franks NP, Lieb WR. 1994. Molecular and cellular mechanisms of general anaesthesia. Nature 367:607-614.

Freidig AP, Hermens JLM. 2001. Narcosis and chemical reactivity QSARs for acute fish toxicity. Quant Struct Activity Relat 19:547-553.

Freidig AP, Verhaar HJM, Hermens JLM. 1999. Comparing the potency of chemicals with multiple modes of action in aquatic toxicology: Acute toxicity due to narcosis versus reactive toxicity of acrylic compounds. Environ Sci Technol 33:3038-3043.
Freidig AP, Hofhuis M, Van Holstijn I, Hermens JLM. 2001. Glutathione depletion in rat hepatocytes: A mixture toxicity study with a,b-unsaturated esters. Xenobiotica 31:295-307.

Gerritsen A, van der Hoeven N, Pielaat A. 1998. The acute toxicity of selected alkylphenols to young and adult Daphnia magna. Ecotoxicol Environ Saf 39:227-232.

Golding CJ, Gobas F, Birch GF. 2007. Characterization of polycyclic aromatic hydrocarbon bioavailability in estuarine sediments using thin-film extraction. Environ Toxicol Chem 26:829-836.

Gülden M, Seibert H. 1997. Influence of protein binding and lipophilicity on the distribution of chemical compounds in in-vitro systems. Toxicol In Vitro 11:479483.

Gülden M, Seibert H, Voss JU. 1994. Inclusion of physicochemical data in quantitative comparisons of in-vitro and in-vivo toxic potencies. ATLA-Altern Lab Anim 22:185-192.

Harder A, Escher BI, Schwarzenbach RP. 2003. Applicability and limitations of QSARs for the toxicity of electrophilic chemicals. Environ Sci Technol 37:49554961.

Harder A, Escher BI, Landini P, Tobler NB, Schwarzenbach RP. 2003. Evaluation of bioanalytical tools for toxicity assessment and mode of toxic action classification of reactive chemicals. Environ Sci Technol 37:4962-4970.

Heagler M, Newman M, Mulvey M, Dixon P. 1994. Allozyme genotype in mosquitofish, Gambusia holbroki, during mercury exposure: Temporal stability, concentration effects and field verification. Environ Toxicol Chem 12:385-395.

Hendriks AJ, Traas TP, Huijbregts MAJ. 2005. Critical body residues linked to octanol-water partitioning, organism composition, and LC50 QSARs: Metaanalysis and model. Environ Sci Technol 39:3226-3236.

Heringa MB. 2004. In: Institute for Risk Assessment Sciences. Utrecht (NL): Utrecht Univ.

Heringa MB, Hermens JL. 2003. Measurement of free concentration using negligible-depletion-solid phase microextraction (nd-SPME). Trends Anal Chem 22:575-587.

Heringa MB, Schreurs R, Busser F, Van Der Saag PT, Van Der Burg B, Hermens JLM. 2004. Toward more useful in vitro toxicity data with measured free concentrations. Environ Sci Technol 38:6263-6270.

Hermens J, Leeuwangh P. 1982. Joint toxicity of mixtures of 8 and 24 chemicals to the guppy (Poecilia reticulata). Ecotoxicol Environ Saf 6:302-310.

Heugens EHW, Jager T, Creyghton R, Kraak MHS, Hendriks AJ, Van Straalen NM, Admiraal W. 2003. Temperature-dependent effects of cadmium on Daphnia magna: Accumulation versus sensitivity. Environ Sci Technol 37:2145-2151.

Hickie BE, McCarty LS, Dixon DG. 1995. A residue-based toxicokinetic model for pulse-exposure toxicity in aquatic systems. Environ Toxicol Chem 14:21872197.

Houston JB. 1994. Utility of in vitro drug metabolism data in predicting in vivo metabolic clearance. Biochem Pharmacol 47:1469-1479.

Huckins JN, Tubergen MW, Manuweera GK. 1990. Semipermeable membrane devices containing model lipids - a new approach to monitoring the bioavailability of lipophilic contaminants and estimating their bioaccumulation potential. Chemosphere 20:533-552.

Hunziker RW, Escher BI, Schwarzenbach RP. 2001. PH-dependence of partitioning of triphenyltin and tributyltin between phosphatidylcholine liposomes and water. Environ Sci Technol 35:3899-3904.

Hunziker RW, Escher BI, Schwarzenbach RP. 2002. Acute toxicity of organotin compounds: Different specific effects on the energy metabolism and role of $\mathrm{pH}$. Environ Toxicol Chem 21:1191-1197.

Jager T, Kooijman S. 2005. Modeling receptor kinetics in the analysis of survival data for organophosphorus pesticides. Environ Sci Technol 39:8307-8314.

Jahnke A, Mayer P, Broman D, McLachlan M. 2009. Equilibrium sampling using polydimethylsiloxane in fish tissue - possibilities and limitations. Chemosphere 77:764-770.

Kishino T, Kobayashi K. 1995. Relation between toxicity and accumulation of chlorophenols at various $\mathrm{pH}$, and their absorption mechanism in fish. Water Res 29:431-442. 
Könemann H. 1981. Quantitative structure-activity relationships in fish toxicity studies. Part 1. Rrelationship for 50 industrial pollutants. Toxicology 19:209221.

Kooijman SALM. 2000. Dynamic energy and mass budgets in biological systems. New York (NY): Cambridge Univ. 424 p.

Kooijman SALM, Bedaux JJM. 1996. Analysis of toxicity tests on Daphnia survival and reproduction. Water Res 30:1711-1723.

Krasowski M, Harrison N. 1999. General anesthetic actions on ligand-gated ion channels. Cell Mol Life Sci 55:1278-1303.

Kwon J-H, Wüthrich T, Mayer P, Escher BI. 2009. Development of a dynamic delivery method for in vitro bioassays. Chemosphere 76:83-90.

Lee JH, Landrum PF. 2006a. Application of multi-component damage assessment model (MDAM) for the toxicity of metabolized PAH in Hyalella azteca. Environ Sci Technol 40:1350-1357.

Lee JH, Landrum PF. 2006b. Development of a multi-component damage assessment model (MDAM) for time-dependent mixture toxicity with toxicokinetic interactions. Environ Sci Technol 40:1341-1349.

Lee JH, Landrum PF, Koh CH. 2002. Prediction of time-dependent PAH toxicity in Hyalella azteca using a damage assessment model. Environ Sci Technol 36:3131-3138

Lee JH, Landrum PF, Koh CH. 2003. Toxicokinetics and time-dependent PAH toxicity in the amphipod Hyalella azteca. Environ Sci Technol 36:31243130 .

Legierse KCHM, Verhaar HJM, Vaes WHJ, De Bruijn JHM, Hermens JLM. 1999. Analysis of the time-dependent acute aquatic toxicity of organophosphorus pesticides: The critical target occupation model. Environ Sci Technol 33:917925.

Legind C, Karlson U, Burken J, Reichenberg F, Mayer P. 2007. Determining chemical activity of (semi)volatile compounds by headspace solid phase microextraction. Anal Chem 79:2869-2876.

Leslie HA, Oosthoek AJP, Busser FJM, Kraak MHS, Hermens JLM. 2002. Biomimetic solid-phase microextraction to predict body residues and toxicity of chemicals that act by narcosis. Environ Toxicol Chem 21:229-234.

Leslie HA, Kraak MHS, Hermens JLM. 2004. Chronic toxicity and body residues of the nonpolar narcotic 1,2,3,4-tetrachlorobenzene in Chironomus riparius. Environ Toxicol Chem 23:2022-2028.

Lienert J, Güdel K, Escher BI. 2007. Screening method for ecotoxicological hazard assessment of 42 pharmaceuticals considering human metabolism and excretory routes. Environ Sci Technol 41:4471-4478.

Lin HI, Berzins DW, Myers L, George WT, Abdelghani A, Watanabe KH. 2004. A Bayesian approach to parameter estimation for a crayfish (Procambarus spp) bioaccumulation model. Environ Toxicol Chem 23:2259-2266.

Lipnick RL. 1989. Hans Horst Meyer and the lipoid theory of narcosis. TiPS 10:265269.

Lipnick RL, Watson K, Strausz A. 1987. A QSAR study of the acute toxicity of some industrial organic chemicals to goldfish. Narcosis, electrophile and proelectrophile mechanism. Xenobiotica 17:1011-1025.

Mackay D. 2004. Finding fugacity feasible, fruitful and fun. Environ Toxicol Chem 23:2282-2289.

Mackay D, Arnot J, Petkova E, Wallace K, Call D, Brooke L, Veith G. 2009. The physicochemical basis of QSARs for baseline toxicity. SAR QSAR Environ Res 20:393-394.

Mancini JL. 1983. A method for calculating effects, on aquatic organisms, of time varying concentrations. Water Res 17:1355-1362.

Mayer P, Reichenberg F. 2006. Can highly hydrophobic organic substances cause aquatic baseline toxicity and can they contribute to mixture toxicity? Environ Toxicol Chem 25:2639-2644.

Mayer P, Tolls J, Hermens L, Mackay D. 2003. Equilibrium sampling devices. Environ Sci Technol 37:184A-191A.

Mayer P, Toräng L, Glæsner N, Jönnson J. 2009. Silicone membrane equilibratormeasuring chemical activity of non-polar chemicals with PDMS micro-tubes immersed directly within tissue and lipids. Anal Chem 81:1536-1542.

McCarty LS, Mackay D. 1993. Enhancing ecotoxicological modeling and assessment: Body residues and modes of toxic action. Environ Sci Technol 27:1719-1728
McCarty LS, Mackay D, Smith AD, Ozburn AD, Dixon DG. 1993. Residue-based interpretation of toxicity and bioconcentration QSARs from aquatic bioassays: Polar narcotic organics. Ecotoxicol Environ Saf 25:253-270.

McCarty LS, Landrum PF, Luoma SN, Meador JP, Merten AA, Shephard BK, von Wezel AP. 2011. Advancing environmental toxicology through chemical dosimetry: external exposures versus tissue residues. Integr Environ Assess Manag 7:7-27.

McKim JM, Schmieder P. 1991. Bioaccumulation: Does it reflect toxicity?. In: Nagel $\mathrm{R}$, Loskill $\mathrm{R}$, editors. Bioaccumulation in aquatic systems: Contributions to the assessment. Weinheim, Germany: VCH Verlagsgesellschaft, p 161-188.

McKim JM, Bradbury SP, Niemi GJ. 1987a. Fish acute toxicity syndromes and their use in the QSAR approach to hazard assessment. Environ Health Persp 71:171186.

McKim JM, Schmieder PK, Carlson RW, Hunt EP, Niemi GJ. 1987b. Use of respiratory-cardiovascular responses of rainbow-trout (Salmo gairdneri) in identifying acute toxicity syndromes in fish.1. Pentachlorophenol, 2,4dinitrophenol, tricaine methanesulfonate and 1-octanol. Environ Toxicol Chem 6:295-312.

Meador JP. 2006. Rationale and procedures for using the tissue-residue approach for toxicity assessment and determination of tissue, water, and sediment quality guidelines for aquatic organisms. Hum Ecol Risk Assess 12:1018-1073.

Meador JP, McCarty L, Escher B, Adams W. 2008. The tissue-residue approach for toxicity assessment: Concepts, issues, application, and recommendations. J Environ Monitor 10:1486-1498.

Meyer HH. 1899. Zur Theorie der Alkoholnarkose. I. Welche Eigenschaft der Anesthetica bedingt ihre narkotische Wirkung. Arch Exp Pathol Pharmakol 42:109-118.

Moody E, Skolnick P. editors 2001. Molecular basis of anesthesia. Boca Raton (FL): CRC. $330 \mathrm{p}$

Naddy RB, Klaine SJ. 2001. Effect of pulse frequency and interval on the toxicity of chlorpyrifos to Daphnia magna. Chemosphere 45:497-506.

Naddy RB, Johnson KA, Klaine SJ. 2000. Response of Daphnia magna to pulsed exposures of chlorpyrifos. Environ Toxicol Chem 19:423-431.

Nagel SC, vom Saal FS, Welshons WV. 1998. The effective free fraction of estradiol and xenoestrogens in human serum measured by whole cell uptake assays: Physiology of delivery modifies estrogenic activity. Proc Soc Exp Biol Med 217:300-309.

National Toxicology Program. 2004. A national toxicology program for the $21 \mathrm{st}$ century: A roadmap for the future. National Institute of Environmental Health Sciences (NIEHS). Available from: http://ntp.niehs.nih.gov/go/vision

Nendza M, Wenzel A. 2006. Discriminating toxicant classes by mode of action. 1. (Eco)toxicity profiles. Environ Sci Pollut Res 13:192-203.

Nendza M, Wenzel A, Wienen G. 1995. Classification of contaminants by mode of action based on in vitro assays. SAR QSAR Environ Res 4:39-50.

Neuwoehner J, Junghans M, Koller M, Escher BI. 2008. QSAR analysis and specific endpoints for classifying the physiological modes of action of biocides in synchronous green algae. Aquat Toxicol 90:8-18.

Neuwoehner J, Fenner K, Escher BI. 2009. Physiological modes of action of fluoxetine and its human metabolites in algae. Environ Sci Technol 43:6830-6837.

Newman M, McCloskey J. 2000. The individual tolerance concept is not the sole explanation for the probit dose-effect model. Environ Toxicol Chem 19:520526.

Nichols JW, McKim JM, Lien GJ, Hoffman AD, Bertelsen SL. 1991. Physiologically based toxicokinetic modeling of three waterborne chloroethanes in rainbow trout (Oncorhynchus mykiss). Toxicol Appl Pharmacol 110:374-389.

Nichols JW, Fitzsimmons PN, Whiteman FW, Dawson TD, Babeu L, Juenemann J. 2004. A physiologically based toxicokinetic model for dietary uptake of hydrophobic organic compounds by fish. I. Feeding studies with $2,2^{\prime}, 5,5^{\prime}$ tetrachlorobiphenyl. Toxicol Sci 77:206-218.

Nishikawa J-I, Mamiya S, Kanayama T. 2004. Involvement of the retinoid $\times$ receptor in the development of imposex caused by organotins in gastropods. Environ SCi Technol 38:6271-6276.

Nuutinen S, Landrum P, Schuler L, Kukkonen J, Lydy M. 2003. Toxicokinetics of organic contaminants in Hyalella azteca. Arch Environ Contam Toxicol 44:467475. 
Obach RS. 1997. Nonspecific binding to microsomes: Impact on scale-up on in vitro intrinsic clearance to hepatic clearance as assessed through examination of warfarin, imipramine and propanolol. Drug Metab Disp 25:1359-1369.

Oravcova J, Bohs B, Lindner W. 1996. Drug-protein binding studies. New trends in analytical and experimental methodology. J Chromatogr B 677:1-28.

Ossiander L, Reichenberg F, McLachlan M, Mayer P. 2008. Immersed solid phase micro extraction to measure chemical activity of lipophilic organics in fatty tissue samples. Chemosphere 71:1502-1510.

Overton E. 1899. Über die allgemeinen osmotischen Eigenschaften der Zelle, ihre vermutlichen Ursachen und ihre Bedeutung für die Physiologie. Vierteljahreszeitschrift der Naturforschenden Gesellschaft in Zürich 44:88-135.

Paustenbach DJ. 2000. The practice of exposure assessment: A state-of-the-art review. J Toxicol Environ Health B Crit Rev 3:179-291.

Péry ARR, Bedaux JJM, Zonneveld C, Kooijman SALM. 2001. Analysis of bioassays with time-varying concentrations. Water Res 35:3825-3832.

Pieters BJ, Jager T, Kraak MHS, Admiraal W. 2006. Modeling responses of Daphnia magna to pesticide pulse exposure under varying food conditions: Intrinsic versus apparent sensitivity. Ecotoxicology 15:601-608.

Rand G, Wells P, McCarty LS. 1995. Introduction to aquatic toxicology. In: R G, editors. Fundamentals of aquatic toxicology 2 nd ed. Washington (DC): Taylor \& Francis, p 3-67.

Reichenberg F, Mayer P. 2006. Two complementary sides of bioavailability: Accessibility and chemical activity of organic contaminants in sediments and soils. Environ Toxicol Chem 25:1239-1245.

Reichenberg F, Smedes F, Jonsson JA, Mayer P. 2008. Determining the chemical activity of hydrophobic organic compounds in soil using polymer coated vials. Chem Central J 2:8

Reinert KH, Giddings JM, Judd L. 2002. Effects analysis of time-varying or repeated exposures in aquatic ecological trisk assessment of agrochemicals. Environ Toxicol Chem 21:1977-1992.

Riley RJ, McGinnity DF, Austin RP. 2005. A unified model for predicting human hepatic, metabolic clearance from in vitro intrinsic clearance data in hepatocytes and microsomes. Drug Metab Dispos 33:1304-1311.

Roberts DW, Costello JF. 2003. Mechanisms of action for general and polar narcosis: A difference in dimension. QSAR Combin Sci 22:226-233.

Sandermann H. 1993. Induction of lipid-protein mismatch by xenobiotics with general membrane targets. Biochim Biophys Acta 1150:130-133.

Schwarzenbach RP, Gschwend PM, Imboden DM. 2003. Environmental organic chemistry 2nd ed. New York (NY): Wiley. 1313 p.

Seeman P, Roth S, Schneider H. 1971. The membrane concentration of alcohol anaesthetics. Biochim Biophys Acta 225:171-184.

Sijm DTHM, Hermens JLM. 2000. Internal effect concentrations: Link between bioaccumulation and ecotoxicity for organic chemicals. In: Beek B, editor. The handbook of environmental chemistry Vol 2J. Berlin (DE): Springer, $p$ 167-199.

Smith KEC, Oostingh GJ, Mayer P. 2010. Passive dosing for producing defined and constant exposure of hydrophobic organic compounds during in vitro toxicity tests. Chem Res Toxicol 23:55-65.

Spycher S, Escher BI, Gasteiger J. 2005. A QSAR model for the intrinsic activity of uncouplers of oxidative phosphorylation. Chem Res Toxicol 18:1858-1867.

Spycher S, Smejtek P, Netzeva TI, Escher BI. 2008. Towards a class-independent quantitative structure-activity relationship model for uncouplers of oxidative phosphorylation. Chem Res Toxicol 21:911-927.

Terada H. 1990. Uncouplers of oxidative phosphorylation. Environ Health Persp 87:213-218.

Timbrell J. 2000. Principles of biochemical toxicology. Washington (DC): Taylor \& Francis. $394 \mathrm{p}$.

Traas TP, van Wezel AP, Hermens JLM, Zorn M, van Hattum AGM, Van Leeuwen CJ. 2004. Environmental quality criteria for organic chemicals predicted from internal effect concentrations and a food web model. Environ Toxicol Chem 23:2518-2527.

Urrestarazu Ramos E, Vaes WHJ, Verhaar HJM, Hermens JLM. 1998. A proposed mechanism for narcosis mode of action. In: Urrestarazu Ramos $E$, editor. Aquatic toxicity of polar narcotic pollutants. Dissertation. RITOX. Utrecht (NL) Utrecht Univ. p 120-129.
Vaes WHJ, Urrestarazu-Ramos E, Verhaar HJM, Seinen W, Hermens JLM. 1996. Measurement of the free concentration using solid-phase microextraction: Binding to protein. Anal Chem 68:4463-4467.

Vaes WHJ, Urrestarazu-Ramos E, Hamwick C, van Holstein I, Blaauboer BJ, Seinen W, Verhaar HJM, Hermens JLM. 1997. Solid phase microextraction as a tool to determine membrane/water partition coefficients and bioavailable concentrations in in-vitro systems. Chem Res Toxicol 10:1067-1072.

Vaes WHM, Urrestarazu-Ramos E, Verhaar H, Hermens JLM. 1998. Acute toxicity of nonpolar versus polar narcosis: Is there a difference? Environ Toxicol Chem 17:1380-1384.

Vallotton N, Eggen RIL, Escher BI, Krayenbuhl J, Chèvre N. 2008. Effect of pulse herbicidal exposure on Scenedesmus vacuolatus: A comparison of two photosystem II inhibitors. Environ Toxicol Chem 27:1399-1407.

Van der Hoeven N, Gerritsen AAM. 1997. Effects of chlorpyrifos on individuals and populations of Daphnia pulex in the laboratory and field. Environ Toxicol Chem 16:2438-2447.

van Hoogen G, Opperhuizen A. 1988. Toxicokinetics of chlorobenzenes in fish. Environ Tox Chem 7:213-219.

van Wezel AP, de Vries DAM, Kostense S, Sijm DTHM, Opperhuizen A. 1995. Intraspecies variation in lethal body burdens of narcotic compounds. Aquat Toxicol 33:325-342.

van Wezel AP, Opperhuizen A. 1995. Narcosis due to environmental pollutants in aquatic organisms: Residue-based toxicity, mechanisms, and membrane burdens. Crit Rev Toxicol 25:255-279.

Veith GD, Broderius SJ. 1990. Rules for distinguishing toxicants that cause type I and type II narcosis syndromes. Environ Health Persp 87:207-211.

Veith GD, Call DJ, Brooke LT. 1983. Structure-toxicity relationships for the fathead minnow, Pimephales promelas: Narcotic industrial chemicals. Can J Fish Aquat Sci 40:743-748

Verhaar HJM, van Leeuwen CJ, Hermens JLM. 1992. Classifying environmental pollutants. 1. Structure-activity relationships for prediction of aquatic toxicity Chemosphere 25:471-491.

Verhaar HJM, Busser FJM, Hermens JLM. 1995. A surrogate parameter for baseline toxicity content of contaminant water: Simulating bioconcentration and counting molecules. Environ Sci Technol 29:726-734.

Verhaar HJM, Urrestarazu-Ramos E, Hermens JLM. 1996. Classifying environmental pollutants. 2. Separation of class 1 (baseline toxicity) and class 2 ("polar narcosis") type compounds based on chemical descriptors. J Chemometrics 10:149-162

Verhaar HJM, De Wolf W, Dyer S, Legierse KCHM, Seinen W, Hermens JLM. 1999. An LC50 vs time model for the aquatic toxicity of reactive and receptormediated compounds. Consequences for bioconcentration kinetics and risk assessment. Environ Sci Technol 33:758-763.

Warne MSJ, Hawker DW. 1995. The number of components in a mixture determines whether synergistic and antagonistic or additive toxicity predominate-the funnel hypothesis. Ecotoxicol Environ Saf 31:23-28.

Warne MSJ, Connell DW, Hawker DW. 1991. Comparison of the critical concentration and critical volume hypotheses of non-specific toxicity for individual compounds. Toxicology 66:187-195.

Wilcockson JB, Gobas FAPC. 2001. Thin-film solid-phase extraction to measure fugacities of organic chemicals with low volatility in biological samples. Environ Sci Technol 35:1425-1431.

Yang RSH, Thomas RS, Gustafson DL, Campain J, Benjamin SA, Verhaar HJM, Mumtaz MM. 1998. Approaches to developing alternative and predictive toxicology based on PBPK/PD and QSAR modeling. Environ Health Persp 6:1385-1393

Yu QM, Chaisuksant Y, Connell D. 1999. A model for non-specific toxicity with aquatic organisms over relatively long periods of exposure time. Chemosphere 38:909-918

Zhao Y, Newman MC. 2004. Shortcomings of the laboratory-derived median lethal concentration for predicting mortality in field populations: Exposure duration and latent mortality. Environ Chem Toxicol 23:2147-2153.

Zhao Y, Newman MC. 2007. The theory underlying dose-response models influences predictions for intermittent exposures. Environ Toxicol Chem 26: 543-547. 